\title{
PDGFR-induced autocrine SDF-1 signaling in cancer cells promotes metastasis in advanced skin carcinoma
}

\author{
Adrià Bernat-Peguera ${ }^{1} \cdot$ Pilar Simón-Extremera ${ }^{1} \cdot$ Victoria da Silva-Diz ${ }^{1,6} \cdot$ Mikel López de Munain $^{1} \cdot$ Laura Díaz-Gil $^{1}$. \\ Rosa M. Penin ${ }^{2} \cdot$ Eva González-Suárez ${ }^{1}$ - Diana Pérez Sidelnikova ${ }^{3} \cdot$ Oriol Bermejo $^{3}$ - Joan Maria Viñals ${ }^{3}$. \\ Francesc Viñals ${ }^{4,5} \cdot$ Purificación Muñoz ${ }^{1}$
}

Received: 12 June 2018 / Revised: 21 January 2019 / Accepted: 22 February 2019 / Published online: 15 March 2019

(c) The Author(s) 2019. This article is published with open access

\begin{abstract}
Advanced and undifferentiated skin squamous cell carcinomas (SCCs) exhibit aggressive growth and enhanced metastasis capability, which is associated in mice with an expansion of the cancer stem-like cell (CSC) population and with changes in the regulatory mechanisms that control the proliferation and invasion of these cells. Indeed, autocrine activation of PDGFR $\alpha$ induces CSC invasion and promotes distant metastasis in advanced SCCs. However, the mechanisms involved in this process were unclear. Here, we show that CSCs of mouse advanced SCCs (L-CSCs) express CXCR4 and CXCR7, both receptors of SDF-1. PDGFR $\alpha$ signaling induces SDF-1 expression and secretion, and the autocrine activation of this pathway in L-CSCs. Autocrine SDF-1/CXCR4 signaling induces L-CSC proliferation and survival, and mediates PDGFR $\alpha$ induced invasion, promoting in vivo lung metastasis. Validation of these findings in patient samples of skin SCCs shows a strong correlation between the expression of SDF1, PDGFRA, and PDGFRB, which is upregulated, along CXCR4 in tumor cells of advanced SCCs. Furthermore, PDGFR regulates SDF-1 expression and inhibition of SDF-1/CXCR4 and PDGFR pathways blocks distant metastasis of human PD/S-SCCs. Our results indicate that functional crosstalk between PDGFR/ SDF-1 signaling regulates tumor cell invasion and metastasis in human and mouse advanced SCCs, and suggest that CXCR4 and/or PDGFR inhibitors could be used to block metastasis of these aggressive tumors.
\end{abstract}

These authors contributed equally: Pilar Simón-Extremera, Victoria da Silva-Diz

Supplementary information The online version of this article (https:// doi.org/10.1038/s41388-019-0773-y) contains supplementary material, which is available to authorized users.

Purificación Muñoz

p.munoz@idibell.cat

1 Cancer Epigenetics and Biology Program (PEBC), Bellvitge Biomedical Research Institute (IDIBELL), Barcelona, Spain

2 Pathology Service, Hospital Universitario de Bellvitge/IDIBELL, Barcelona, Spain

3 Plastic Surgery Unit, Hospital Universitario de Bellvitge/ IDIBELL, Barcelona, Spain

4 Laboratory of Translational Research, Catalan Institute of Oncology (ICO/IDIBELL), Barcelona, Spain

5 Unitat de Bioquímica i Biologia Molecular, Departament de Ciències Fisiològiques, Universitat de Barcelona-IDIBELL, Barcelona, Spain

6 Present address: Rutgers Cancer Institute of New Jersey, Rutgers University, New Brunswick, NJ, USA

\section{Introduction}

Squamous cell carcinoma (SCC) is the second most common non-melanoma skin cancer in humans, accounting for $20 \%$ of cutaneous malignancies $[1,2]$. Most invasive skin SCCs conserve epithelial differentiation traits and are considered to be well-differentiated SCCs (WD-SCCs). A subset of SCCs show poorly differentiated features and eventually become spindle-shaped (PD/S-SCCs), the latter characteristic being associated with enhanced recurrence, metastasis, and reduced patient survival [3-5]. Most skin SCC lesions are treated by surgical excision. Although high risk and metastatic skin SCCs are treated with adjuvant radiotherapy or chemotherapy, the clinical benefits of these treatments have been limited [6]. Therefore, it is important to design targeted therapies that efficiently block the aggressive growth and metastasis of advanced SCCs.

Mouse skin SCC cells expressing CD34 and $\alpha 6$-integrin, or Sox 2 are enriched in tumor-initiating or cancer stem-like cells (CSCs) relative to the bulk of tumor cells. This cell population is responsible for long-term SCC growth and 
metastasis [7-9]. Highly aggressive and metastatic mouse $\mathrm{PD} / \mathrm{S}-\mathrm{SCC}$ arise from the malignant progression of WDSCCs $[10,11]$ and during this process, the CSC population is dramatically expanded and regulatory mechanisms controlling CSC proliferation and dissemination change. FGFR1 signaling is induced in the CSCs of advanced PD/SSCCs to promote aggressive growth. The PDGFR $\alpha$ pathway is also activated by an autocrine way in these CSCs, which promotes CSC invasion and enhances metastasis in PD/S-SCCs [11]. However, the mechanisms involved in PDGFR $\alpha$-induced metastasis remain unclear.

The chemokine SDF-1 (CXCL12), which binds to $G$ protein-coupled receptors CXCR4 and CXCR7, plays an important role in tumor growth and metastasis in different tumor types [12-15]. Stromal fibroblasts and cancer cells produce SDF-1 [16], which stimulates cancer cell proliferation and is responsible for recruiting CXCR4expressing endothelial progenitor cells, thereby increasing tumor angiogenesis $[17,18]$. CXCR4 is expressed by CSCs in various tumor types [19-21]. SDF-1/CXCR4 signaling increases the self-renewal of breast and brain CSCs [22-24], and the epithelial-to-mesenchymal transition (EMT) program and metastasis in sarcomas, breast, pancreatic, colon, and liver cancer cells [24-27]. CXCR7/ RDC1 receptor is expressed by immune, endothelial, and tumor cells and binds SDF-1 with high affinity [28]. Although CXCR7 was thought to act as a scavenger receptor [29], it was recently demonstrated that SDF-1/ CXCR7 signaling induces CSC proliferation/survival and EMT [30, 31], supporting growth and metastasis in different tumor types.

SDF-1 is significantly upregulated in stromal fibroblasts of human skin SCCs relative to normal skin [32], and CXCR4 is upregulated in metastatic SCCs in comparison to normal skin and non-metastatic skin carcinomas [33], whereas CXCR7 expression is induced in $70 \%$ of patient skin SCC samples and is associated with cancer cell survival [34]. However, the role of the SDF1/CXCR4/CXCR7 pathway in cutaneous SCCs has been unclear. Here, we demonstrate that functional crosstalk between PDGFR/ SDF-1 pathways induces the autocrine activation of SDF-1/ CXCR4 signaling in cancer cells of mouse and human PD/ S-SCCs, which promotes distant metastasis.

\section{Results}

\section{SDF-1 and CXCR4 expression is upregulated in mouse advanced SCCs}

To determine the relevance of SDF-1 signaling in skin SCC growth and metastasis, we initially compared the expression of this chemokine and $\mathrm{Cxcr} 4$ and $\mathrm{Cxcr} 7$ receptors in early WD-SCCs and advanced PD/S-SCCs of two different lineages of mouse skin SCC progression (OT7 and OT14). In each of these lineages, PD/S-SCCs were generated after the serial engraftment of their WD-SCC precursors in immunodeficient mice [11]. We found that $S d f 1$ expression, which was weakly detected in early SCCs, was upregulated in PD/S-SCCs (Fig. 1a). In WD-SCCs, Sdf1 was expressed by fibroblasts (Fig. 1b) and immunodetected in stromal cells (Fig. 1c), as previously described [32, 35], whereas tumor cells and $\mathrm{CD}_{4} 5^{+}$immune cells (deficient in T-cell in nude immunodeficient mice) exhibited a faint or undetectable Sdf1 expression (Fig. 1b). In contrast, SDF-1 was strongly upregulated in tumor cells of PD/S-SCCs (Fig. 1c), reaching similar levels to those expressed by fibroblasts (Fig. 1b).

Cxcr4 and Cxcr7 expression was upregulated in advanced SCCs relative to WD-SCCs (Fig. 1d). An expansion of CXCR4-expressing tumor cells was detected by immunohistochemistry in PD/S-SCCs, as compared to WD-SCCs (Supplementary Fig. 1A). Flow cytometry analysis showed that around 3-7\% of tumor cells expressed CXCR4 ( $\alpha 6$-integrin ${ }^{+} / \mathrm{CXCR}^{+}{ }^{+}$cells) in WD-SCCs, and this frequency was significantly increased in PD/S-SCCs (Fig. 1e, f). $\mathrm{CXCR}^{+}$cells were more frequent than CXCR4-expressing cells in early and advanced SCCs (Supplementary Fig. 1A and 1B). Accordingly, 60-70\% of tumor cells expressed CXCR7 ( $\alpha 6$-integrin ${ }^{+} / \mathrm{CXCR} 7^{+}$ cells) in WD-SCCs and this frequency was not significantly increased in PD/S-SCCs (Fig. 1e, f). These results suggest that increased levels of $C x c r 7$ mRNA detected in advanced tumors may be associated with a different stromal/tumor cells ratio in WD-SCCs and PD/S-SCCs [36, 37].

Analysis of the ligand and receptors in the CSC population ( $\alpha 6$-integrin ${ }^{+} / \mathrm{CD} 4^{+}$cells) showed that CSCs isolated from PD/S-SCCs (L-CSCs) strongly expressed Sdfl, whereas the expression of this chemokine was practically undetectable in CSCs of WD-SCCs (E-CSCs) (Fig. 1g). CXCR4 was mostly expressed by a subpopulation (5-20\%) of E-CSCs (Fig. 1h, i), whereas CXCR7 was detected in CSC and non-CSC populations, and around 50-80\% of E-CSCs expressed CXCR7. Furthermore, the percentage of CXCR4- or CXCR7expressing $\alpha 6$-integrin ${ }^{+} / \mathrm{CD} 34^{+}$cells was not significantly altered in PD/S-SCCs compared with WD-SCCs (Fig. 1h, i). Since the $\alpha 6$-integrin ${ }^{+} / \mathrm{CD} 34^{+}$-CSC population is expanded in advanced tumors (Fig. 1i; see [7, 11]), our results indicate that the global amount of $\mathrm{CXCR}^{+}{ }^{+} \mathrm{CSCs}$ was increased in the PD/S-SCCs.

It is important to highlight that similar $S d f 1$ and Cxcr4 upregulation was observed in primary PD/S-SCCs (spontaneously developed in K14-HPV16 mice [11]) and in PD/SSCCs that were engrafted in syngeneic immunocompetent mice, relative to their respective WD-SCCs (Supplementary 
A

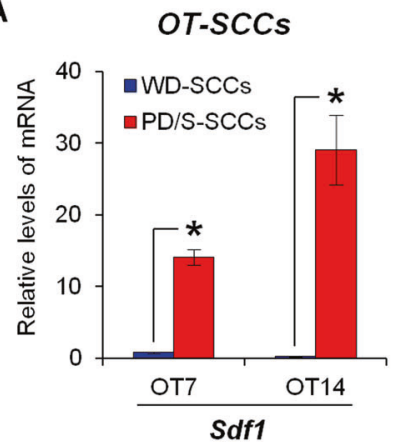

D

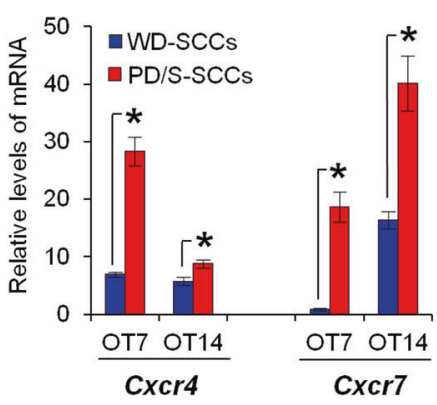

$\mathbf{F}$

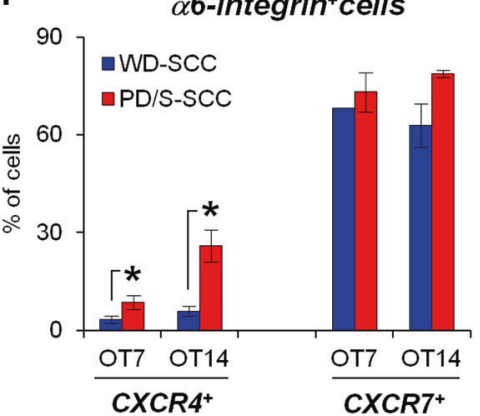

B

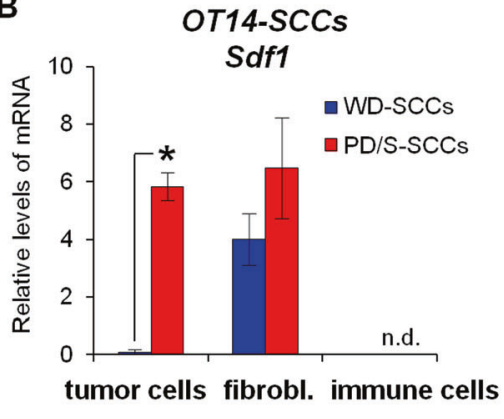

C

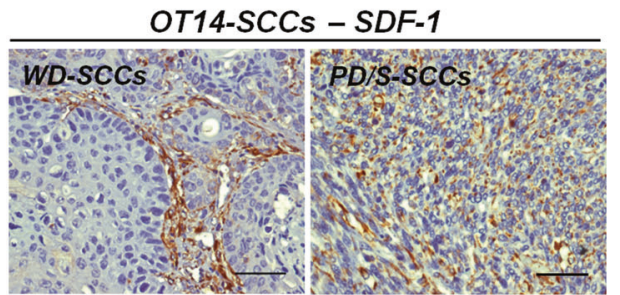

E

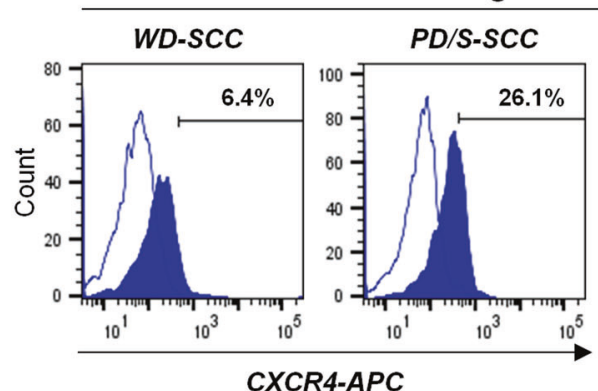

a6-integrin ${ }^{+}$cells in OT14-tumors

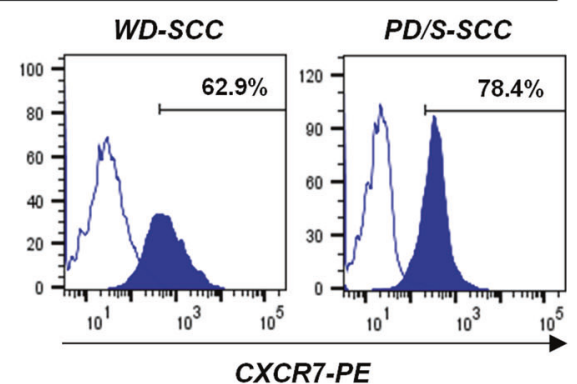

CXCR7-PE
H

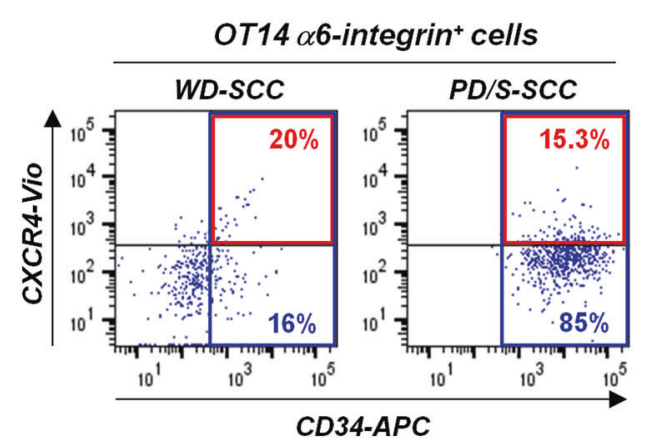

I

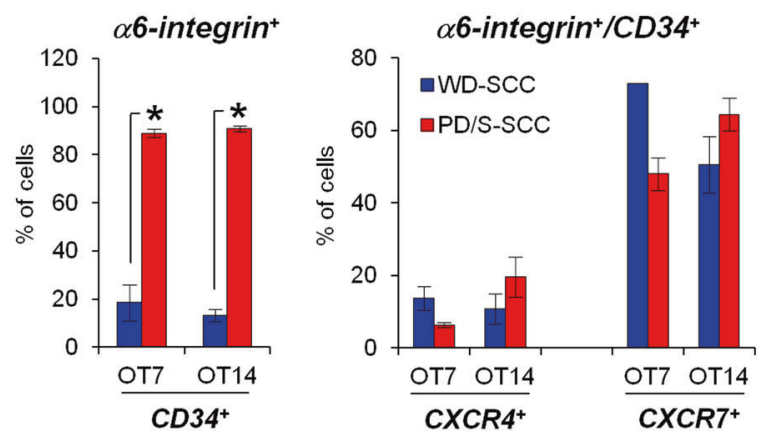

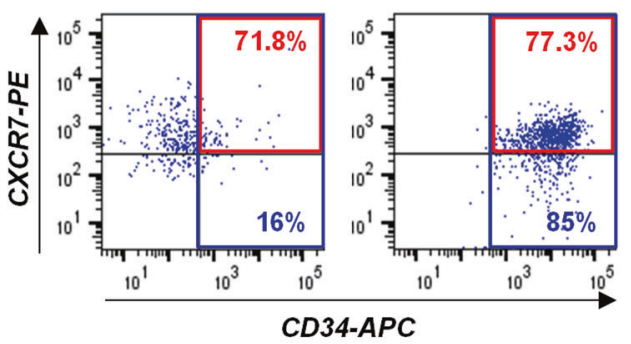

Fig. 1C and 1D). SDF-1 expression was significantly induced in tumor and stromal cells (Supplementary Fig. 1E), and an expansion of CXCR4-expressing CSCs was detected in $\mathrm{PD} / \mathrm{S}-\mathrm{SCC}$ generated in immunocompetent mice (Supplementary Fig. $1 \mathrm{~F}-1 \mathrm{H}$ ), indicating that SDF-1 signaling may be activated in CSCs of advanced tumors independently of the immune status of the mice.

\section{Autocrine SDF-1 signaling promotes PD/S-SCC CSC proliferation and invasion}

To determine whether an autocrine SDF-1 signaling is induced in L-CSCs, we isolated tumor cells from WD-SCCs (WD cells) and PD/S-SCCs (PD/S cells), which were maintained in culture. We previously demonstrated that 
Fig. 1 CSCs of mouse advanced skin SCCs express CXCR4 and CXCR7 and up-regulate the expression of $S d f 1$. a, b Mean $( \pm$ SE) levels of Sdf1 mRNA relative to Gapdh, as quantified by qRT-PCR in WDSCCs and PD/S-SCCs (three different samples per group) of OT7 and OT14 lineages (a), and in tumor cells ( $\alpha 6$-integrin ${ }^{+} / \mathrm{CD}^{-} 5^{-} / \mathrm{CD} 31^{-}$ cells), immune cells ( $\alpha 6$-integrin ${ }^{-} / \mathrm{EpCAM}^{-} / \mathrm{CD} 45^{+} / \mathrm{CD} 31^{-}$cells), and fibroblasts ( $\alpha 6$-integrin ${ }^{-} / \mathrm{EpCAM}^{-} / \mathrm{CD} 45^{-} / \mathrm{CD} 31^{-}$cells) isolated from OT14 WD-SCCs and PD/S-SCCs (two different samples per group) by FACS-sorter (b). c Representative images of the SDF-1 immunodetection in paraffin sections of WD-SCCs and PD/S-SCCs of OT14 lineage. Scale bar, $100 \mu \mathrm{m}$. d Mean $( \pm$ SE) levels of the indicated mRNAs, relative to Gapdh, as quantified by qRT-PCR in WD-SCCs and PD/S-SCCs (three different samples per group) of OT7 and OT14 lineages. e Representative results of quantification of the indicated cell populations in OT14 WD-SCCs and PD/S-SCCs by flow cytometry. Percentage of $\alpha 6$-integrin ${ }^{+} / \mathrm{CXCR} 4^{+}$and $\alpha 6$-integrin ${ }^{+} / \mathrm{CXCR}^{+}$cells is indicated in each panel. $f$ Mean percentages $( \pm$ SE) of cell populations analyzed in e (3-10 different tumor samples per group). $\mathbf{g}$ Mean $( \pm \mathrm{SE})$ Sdf1 mRNA levels relative to Gapdh in E-CSCs and L-CSCs (three different samples per group) isolated by FACS-sorter from the indicated tumors. h Flow cytometry quantification of $\mathrm{CXCR}^{+}$and $\mathrm{CXCR}^{+}$cells (red numbers) into the $\alpha 6$-integrin ${ }^{+} / \mathrm{CD} 34^{+} \mathrm{CSC}$ population (blue numbers) of the indicated tumors. i Mean percentage $( \pm$ SE) of the indicated cell populations in WD-SCCs and PD/S-SCCs, as quantified in $\mathbf{h} .{ }^{*}$, significant differences between compared groups $(t$-test; $P \leq 0.05)$. n.d. not detected

these primary cultures were enriched in tumor-initiating cells that conserved the molecular traits of parental SCC CSCs [11]. In this regard, $\mathrm{PD} / \mathrm{S}$ cells expressed and secreted higher levels of SDF-1 than WD cells (Fig. 2a, b). In addition, $\mathrm{PD} / \mathrm{S}$ cells expressed $C x c r 4$ and $C x c r 7$, showing a lower expression of Cxcr4 than $\mathrm{Cxcr} 7$ (Fig. 2c). Accordingly, $40-60 \%$ of $\alpha 6$-integrin ${ }^{+} / \mathrm{CD} 34^{+}-\mathrm{CSC}$ in $\mathrm{PD} / \mathrm{S}$ cell cultures expressed CXCR7, whereas $6-16 \%$ of $\alpha 6$-integrin ${ }^{+} / \mathrm{CD} 34^{+}$-CSCs expressed CXCR4 (Fig. 2d; Supplementary Fig. 2A and 2B), and most CXCR4 ${ }^{+}$-CSCs expressed CXCR7 (Supplementary Fig. 2C).

To determine the impact of SDF-1 signaling on proliferation, $\mathrm{PD} / \mathrm{S}$ cells growing in basal medium or supplemented with purified chemokine were treated with AMD3100, an antagonist of CXCR4 [38]. AMD3100 treatment significantly inhibited the proliferation/survival of $\mathrm{PD} / \mathrm{S}$ cells under basal conditions, and addition of SDF-1 to the medium did not alter or only slightly induced the proliferation of PD/S cells (Fig. 2e; Supplementary Fig. 2D). Similarly, the proliferation of $\mathrm{PD} / \mathrm{S}$ cells with interfered expression of SDF-1 (Supplementary Fig. 2E) was significantly reduced in comparison with that of $\mathrm{PD} / \mathrm{S}$ control cells (Fig. 2f; Supplementary Fig. 2F), indicating that the autocrine activation of SDF-1 signaling promotes $\mathrm{PD} / \mathrm{S}$ cell proliferation. The expression of $C x c r 4$, but not of $C x c r 7$, was significantly reduced in SDF-1 knocked-down cells (Supplementary Fig. 2G), suggesting that $\mathrm{Cxcr} 4$ expression is regulated directly or indirectly by SDF-1 signaling.

$\mathrm{PD} / \mathrm{S}$ cells showed in vitro a strong migration and invasion capacity, which was associated with enhanced distant metastasis in advanced SCCs [11]. We observed that AMD3100 treatment as well as SDF-1 abrogation significantly reduced the invasive capability of $\mathrm{PD} / \mathrm{S}$ cells (Fig. 2h, i). These results indicate that autocrine SDF-1 signaling promotes CSC motility and invasion, which may consequently favor CSC dissemination and metastasis.

\section{CXCR4 inhibition blocks distant metastasis in mouse PD/S-SCCs}

As SDF-1 signaling can be activated through CXCR4 and CXCR7, we evaluated the role of each of these receptors in regulating $\mathrm{PD} / \mathrm{S}-\mathrm{SCC}$ growth and metastasis. For this purpose, we knocked down the expression of $\mathrm{Cxcr} 4$ and $\mathrm{Cxcr} 7$ in PD/S cells of different SCC lineages (Supplementary Fig. 3A). Abrogation of CXCR4 did not affect the expression of Cxcr7, but did significantly reduce the expression of $S d f 1$ (Supplementary Fig. 3B). In contrast, CXCR7 knockdown induced the downregulation of Cxcr4, whereas $S d f 1$ expression was significantly reduced only in OT7 $\mathrm{PD} / \mathrm{S}$ cells (Supplementary Fig. 3B). As OT7 cells showed a lower level of $\mathrm{Cxcr} 4$ expression and a smaller percentage of CXCR4 ${ }^{+}$-CSCs than OT14 cells (Fig. 2c, d), CXCR7 knockdown may lead to an almost complete abrogation of Cxcr4 in OT7 cells, in turn causing a significant downregulation of $S d f 1$. Therefore, these data suggest that the expression of Cxcr4 is finely regulated by the levels of SDF-1 and CXCR7 and, in turn, that CXCR4 regulates the expression of the ligand.

CXCR4 knockdown significantly reduced the proliferation of $\mathrm{PD} / \mathrm{S}$ cells in both lineages, whereas CXCR7 knockdown only inhibited the proliferation of OT7 PD/S cells, in accordance with the strong downregulation of $S d f 1$ observed in these cells (Fig. 2g; Supplementary Fig. 3C).

In order to determine the impact of CXCR4 and CXCR7 on PD/S-SCC growth and metastasis, we engrafted sh-control, sh-CXCR4, and sh-CXCR7 PD/S cells from the OT14 lineage in immunodeficient mice. sh-CXCR4 tumors showed a reduced percentage of $\alpha 6$-integrin ${ }^{+} / \mathrm{CXCR} 4^{+}$ tumor cells, and specifically of CXCR4-expressing CSCs, compared with sh-control tumors, whereas the percentage of CXCR7-expressing CSCs was not affected (Supplementary Fig. 3D-3F). In contrast to CXCR7 knocked-down tumors, sh-CXCR4 tumors grew less than control tumors (Fig. 3a), in accordance with the significant reduction in the percentage of proliferating tumor cells observed in the CXCR4deficient tumors (Supplementary Fig. 3G and 3H). To determine the impact of CXCR4 signaling on tumor growth under an immunocompetent background, sh-control and shCXCR4 PD/S cells were engrafted in syngeneic immunocompetent mice. In contrast to that observed in immunodeficient mice, tumor growth was not significantly blocked after CXCR4 abrogation (Fig. 3b; Supplementary Fig. 3I), or 
A

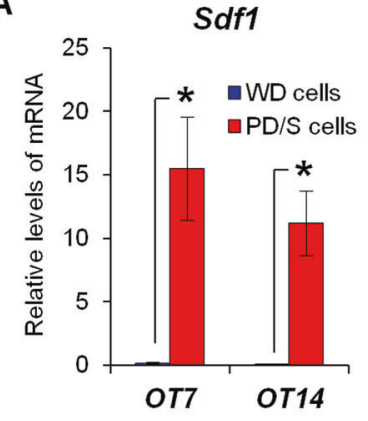

D

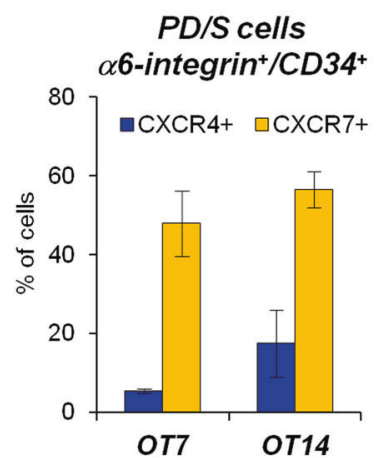

G

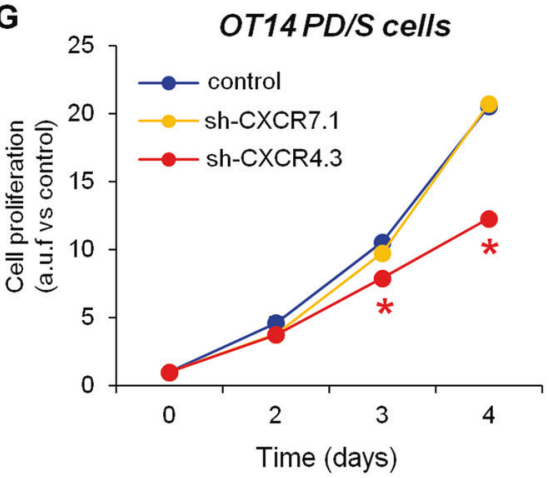

B

E
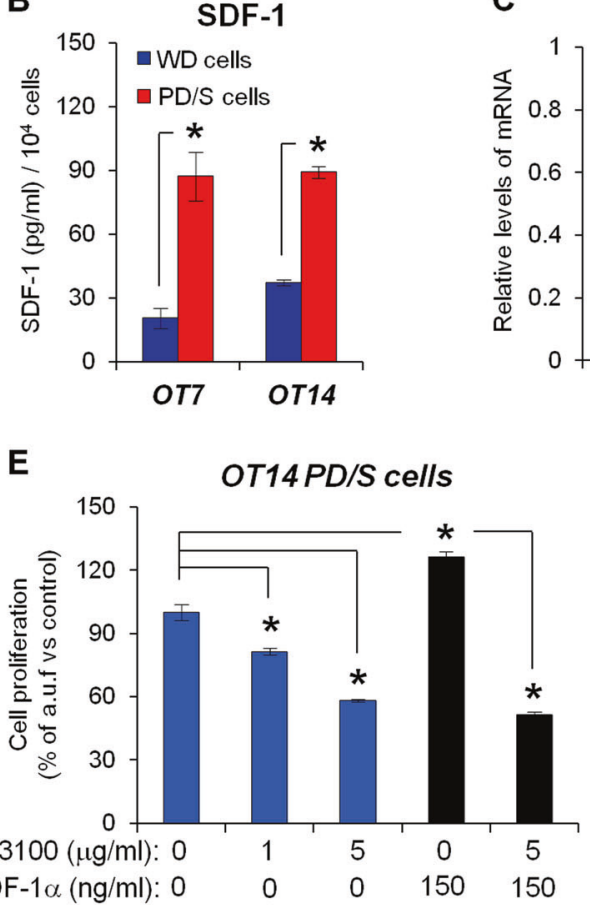

H

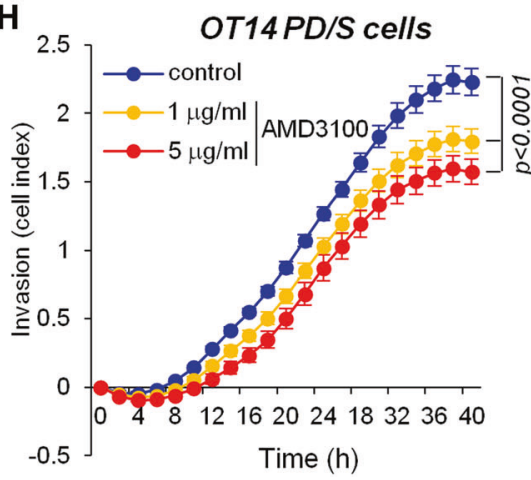

C

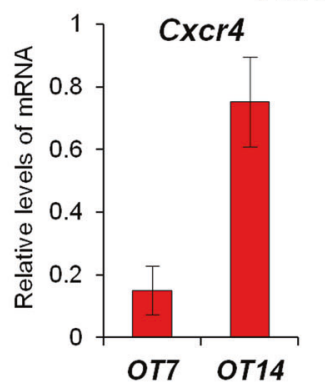

$\mathbf{F}$

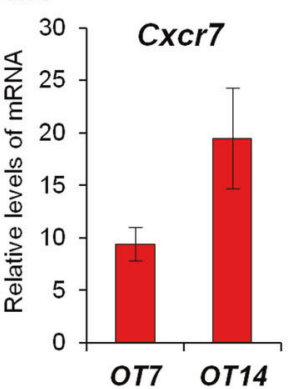

OT14 PD/S cells

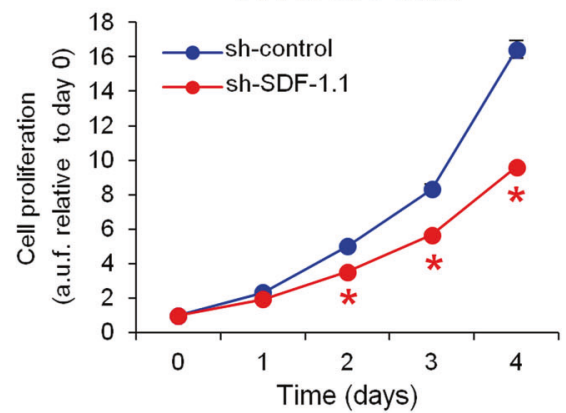

I

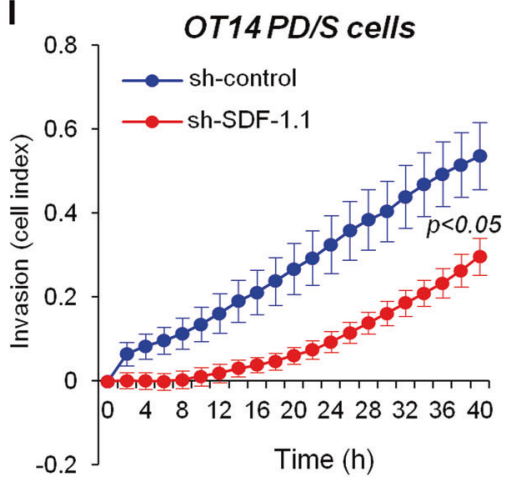

Fig. 2 Autocrine SDF-1 signaling promotes L-CSC proliferation and invasion. a Mean $( \pm \mathrm{SE})$ of $S d f 1 \mathrm{mRNA}$ levels relative to Gapdh, as quantified by qRT-PCR in in vitro growing tumor cells isolated from WD-SCC (WD cells) and PD/S-SCCs (PD/S cells) of the indicated tumor lineages (two different primary cell cultures per tumor type and lineage). b SDF-1 concentration in the culture medium of the indicated cells (two primary culture cells per group and lineage), as quantified by ELISA assays. c Mean $( \pm \mathrm{SE}) \mathrm{Cxcr} 4$ and $C x c r 7$ mRNA levels, relative to Gapdh, in $\mathrm{PD} / \mathrm{S}$ cell cultures (three samples per group) of the indicated lineages. $\mathbf{d}$ Mean percentages $( \pm \mathrm{SE})$ of CXCR4- or CXCR7expressing $\alpha 6$-integrin ${ }^{+} / \mathrm{CD} 34^{+}$cells (three samples per group) in $\mathrm{PD} /$ $\mathrm{S}$ cells of OT7 and OT14 lineages, as quantified by flow cytometry. e Cell proliferation upon SDF-1 $\alpha$ and/or AMD3100 treatment, as measured by MTT. Results show means $( \pm \mathrm{SE})$ of arbitrary units of fluorescence (a.u.f.) in treated cells relative to cells growing without SDF- $1 \alpha$ and inhibitor. f Proliferation kinetics (means \pm SE of a.u.f. relative to day 0) of control $\mathrm{PD} / \mathrm{S}$ cells (sh-control) or SDF-1 interfered cells (sh-SDF-1.1), as measured by MTT. Representative results of two independent assays. g Proliferation kinetics (means \pm SE of a.u.f.) of control PD/S cells (sh-control) and PD/S cells with CXCR4 (shCXCR4.3) or CXCR7 (sh-CXCR7.1) mRNA interference, as measured by MTT. Representative results of three independent assays. $\mathbf{h}, \mathbf{i}$ Comparison of invasion capacity (mean cell index \pm SE) of PD/S cells upon control or AMD3100 treatment (h), or in SDF-1 interfered $\mathrm{PD} / \mathrm{S}$ cells (i) in $\mathrm{x}$-CELLingence real-time analysis. Representative results of two independent assays. *, significant differences between the compared groups $(t$-test; $P \leq 0.05)$ after AMD3100 treatment (Fig. 3c), suggesting that the effect of CXCR4 inhibition on tumor growth may be tumor microenvironment-dependent.

Furthermore, immunodeficient mice carrying sh-CXCR4 $\mathrm{PD} / \mathrm{S}$-SCCs developed significantly less metastatic foci in the lungs than mice carrying sh-control tumors (Fig. 3d, e), in the absence of alterations in the tumor angiogenesis, as indicated by the unaltered frequency of $\mathrm{CD} 31^{+}$vessels (Fig. 3f, g) and the conserved expression of Vegfr2, a marker of endothelial cells (Supplementary Fig. 3J). Despite the number of metastases generated from CXCR7-interfered $\mathrm{PD} / \mathrm{S}$-SCCs was lower than from sh-control tumors, this 

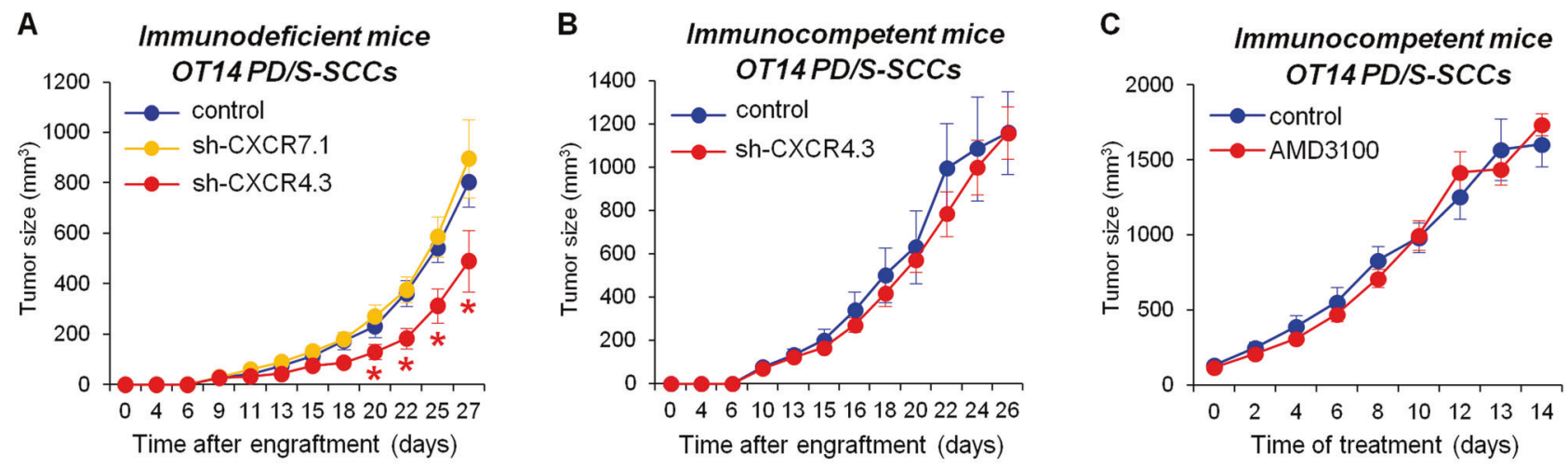

D

Immunodeficient mice

OT14-PD/S-SCCs - lung metastasis

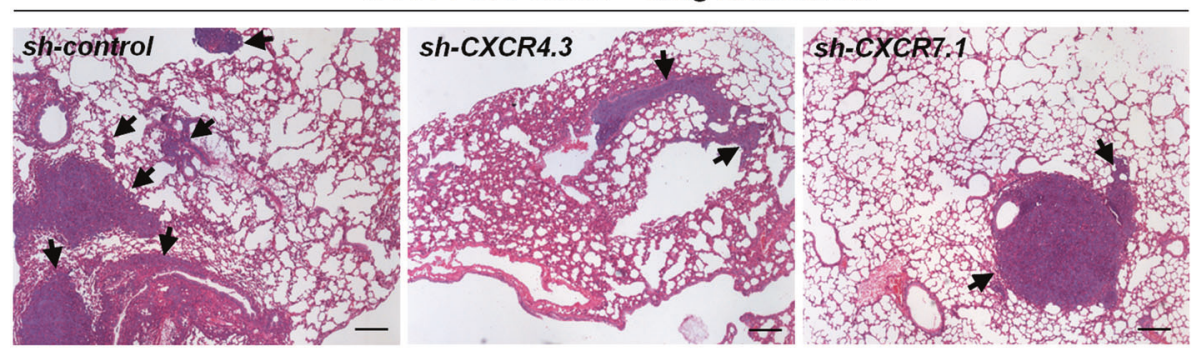

E Immunodeficient mice

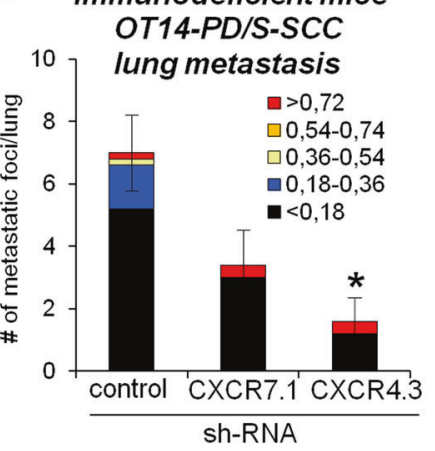

F

Immunodeficient mice OT14PD/S-SCCs - CD31
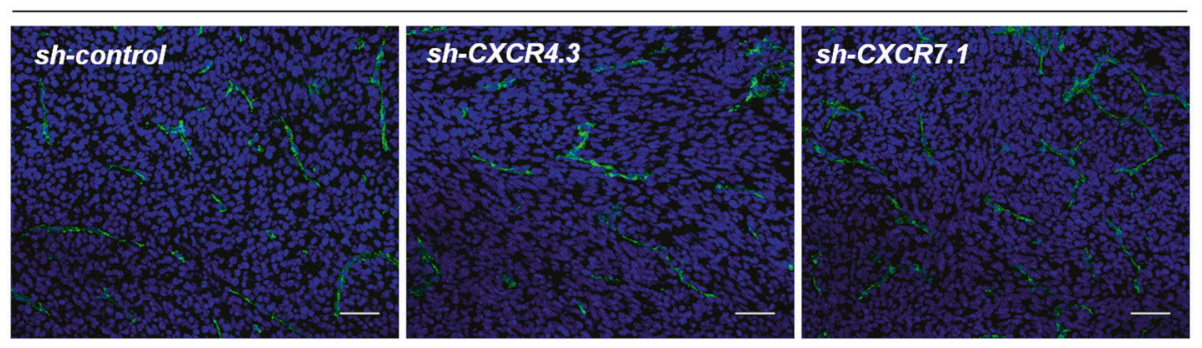

G

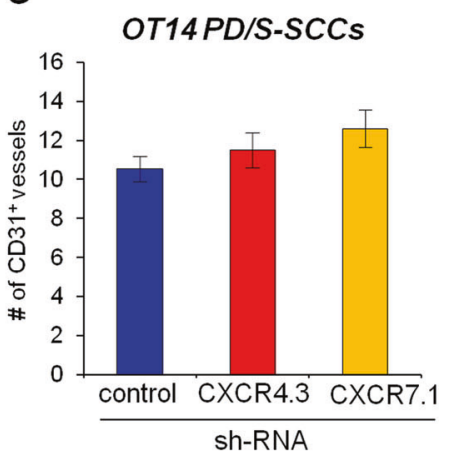

H

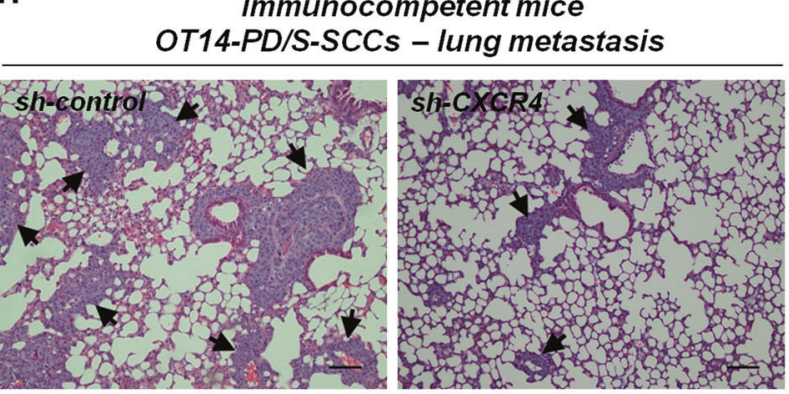

difference was not significant (Fig. 3d, e) and could be associated with the downregulation of $\mathrm{Cxcr} 4$ expression induced by CXCR7 knockdown.

Similarly, CXCR4 abrogation in L-CSCs and CXCR4 pharmacological inhibition by AMD3100 treatment
I

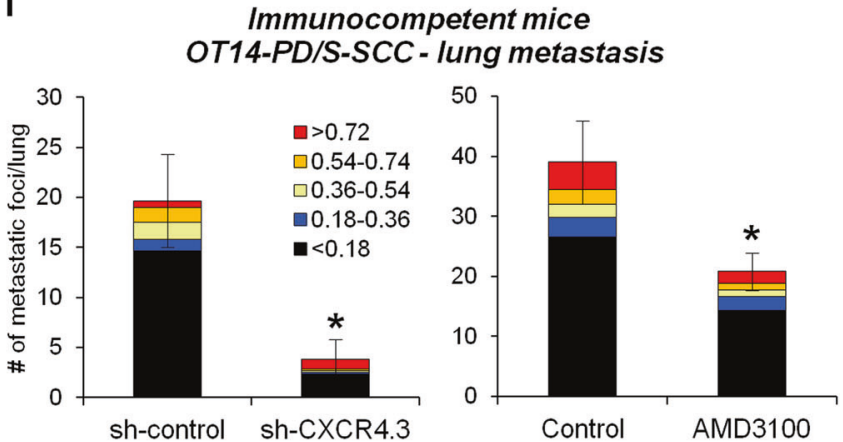

significantly reduced lung metastasis development in immunocompetent mice (Fig. 3h, i). Taken together, these results indicate that $\mathrm{CXCR} 4$ inhibition blocks distant metastasis of PD/S-SCCs, independently of the immune status of mice. 
Fig. 3 CXCR4 inhibition in L-CSCs blocks mouse PD/S-SCC metastasis. a, b Growth kinetics (means $\pm \mathrm{SE}$ of tumor size, $\mathrm{mm}^{3}$ ) of control (sh-control), CXCR4 (sh-CXCR4.3), and CXCR7 knockeddown (sh-CXCR7.1) PD/S-SCCs (eleven tumors per group) in immunodeficient mice (a), and of sh-control and sh-CXCR4.3 PD/SSCCs (six and ten tumors, respectively) in syngeneic immunocompetent mice (b). c Growth kinetics (means \pm SE of tumor size, $\mathrm{mm}^{3}$ ) of control and AMD3100 treated PD/S-SCCs (seven tumors per group) growing in immunocompetent mice. d Metastatic lesions (indicated by black arrows) in the lungs of immunodeficient mice carrying sh-control, sh-CXCR4.3, and sh-CXCR7.1 PD/S-SCCs. Scale bar, $200 \mu \mathrm{m}$. e Mean of metastatic foci $( \pm$ SE) per lung section (categorized by size, $\mathrm{mm}^{2}$ ) in mice with the indicated PD/S-SCC types (5-6 mice per group), as determined in $\mathbf{d}$. f Representative images of the immunodetection of CD31 ${ }^{+}$vessels in sh-control, sh-CXCR4.3, and sh-CXCR7.1 PD/S-SCCs. Scale bar, $40 \mu \mathrm{m}$. g Mean frequency $( \pm$ SE; 3-4 tumor samples per group) of $\mathrm{CD} 31^{+}$vessels per tumor section, as determined in $\mathbf{f}$. $\mathbf{h}$ Metastatic lesions (indicated by black arrows) in the lungs of immunocompetent mice carrying the sh-control and shCXCR4.3 PD/S-SCCs. Scale bar, $200 \mu \mathrm{m}$. i Mean of metastatic foci $\left( \pm\right.$ SE) per lung section (categorized by size, $\left.\mathrm{mm}^{2}\right)$ in mice with the indicated $\mathrm{PD} / \mathrm{S}-\mathrm{SCC}$ types and treatments (six mice per group). *, significant differences between the compared groups $(t$-test; $P \leq 0.05)$

\section{SDF-1 abrogation in L-CSCs inhibits distant metastasis}

To determine the impact of $S d f 1$ upregulation in L-CSCs on $\mathrm{PD} / \mathrm{S}-\mathrm{SCC}$ growth and metastasis, we engrafted sh-control and sh-SDF-1 PD/S cells in immunodeficient mice. Tumor latency and growth kinetics were similar in sh-control and sh-SDF-1 PD/S-SCCs (Fig. 4a; Supplementary Fig. 4A), even though the interference of the chemokine expression in tumor cells was maintained during tumor growth (Supplementary Fig. 4B). Furthermore, a reduction in the percentage of $\alpha 6$-integrin ${ }^{+} / \mathrm{CD} 34^{+} / \mathrm{CXCR} 4^{+} \mathrm{CSCs}$, but not of $\alpha 6-$ integrin ${ }^{+} / \mathrm{CD} 34^{+} / \mathrm{CXCR}^{+} \mathrm{CSCs}$, was observed in sh-SDF1 tumors, compared with sh-control tumors (Fig. 4b; Supplementary Fig. 4C and 4D), in accordance with the downregulated expression of Cxcr4 observed in sh-SDF-1interfered PD/S cells (Supplementary Fig. 2G).

SDF-1 abrogation dramatically reduced the development of lung metastasis from PD/S-SCCs (Fig. 4c, d; Supplementary Fig. 4E). As stroma-derived SDF-1 promotes the recruitment of endothelial cells at tumors [39], SDF-1 interference in tumor cells might also alter tumor angiogenesis, blocking metastasis. However, a similar density of $\mathrm{CD} 31^{+}$vessels and Vegfr2 expression were observed in control and SDF-1-interfered tumors (Fig. 4e-g). Metastasis blockage was not related to the attenuation of the EMT program, as the expression of EMT-inducer transcription factors (Supplementary Fig. 4F) and the repressed expression of $C d h l$ (E-Cadherin) (data not shown) was not altered in sh-SDF-1 tumor cells. No changes in the expression of SDF-1 were detected in the fibroblasts isolated from shSDF-1 PD/S-SCCs, as compared with the control tumors (Fig. 4h). These results suggest that a paracrine activation of
SDF-1 signaling or the activation of other stroma-induced signaling pathways can support tumor cell proliferation, but not distant metastasis.

Taken together, these results indicate that abrogation of autocrine SDF-1 signaling reduces the migration and invasion capacity of CSCs of PD/S-SCCs, blocking the development of metastasis of these advanced tumors.

\section{Functional PDGFRa/SDF-1 signaling crosstalk promotes L-CSC invasion in mouse PD/S-SCCs}

PDGFR $\alpha$ signaling promotes L-CSC invasion and PD/SSCC metastasis [11], so we tested whether activation of this pathway regulates SDF-1 signaling in SCC CSCs. Flow cytometry assays demonstrated that whereas the scarce population of CXCR $4^{+}$WD cells did not express PDGFR $\alpha$, most $\mathrm{PD} / \mathrm{S}$ cells, including $\mathrm{CXCR} 4^{+} \mathrm{PD} / \mathrm{S}$ cells, exhibited high levels of PDGFR $\alpha$ (Fig. 5a, b). PDGFR $\alpha$ knockdown (Fig. 5c) significantly reduced $S d f 1$ expression in $\mathrm{PD} / \mathrm{S}$ cells, as determined by quantitative reverse transcriptase PCR (RT-PCR) and enzyme-linked immunosorbent assay (ELISA) assays (Fig. 5d, e). In turn, SDF-1 knockdown reduced the expression of PDGFR $\alpha$ (Fig. 5f; Supplementary Fig. 5A and 5B), whereas the ectopic expression of SDF-1 in $\mathrm{PD} / \mathrm{S}$ cells (Supplementary Fig. 5C) further upregulated the expression of PDGFR $\alpha$ (Fig. $5 \mathrm{~g}, \mathrm{~h}$ ), indicating that the activity of each of these signaling pathways modulates the activity of the other. In order to determine whether PDGFR $\alpha$-induced invasion of $\mathrm{PD} / \mathrm{S}$ cells is mediated by SDF-1 signaling, we compared the invasion capability of these cells under control conditions, upon inhibition of PDGFR $\alpha$ signaling by treatment with Imatinib, an inhibitor of PDGFR, and in Imatinib-treated SDF- $1 \alpha$-overexpressing $\mathrm{PD} / \mathrm{S}$ cells. Our results demonstrated that whereas Imatinib treatment significantly reduced the invasion of $\mathrm{PD} / \mathrm{S}$ cells, the ectopic expression of SDF-1 restored the invasion of Imatinib-treated $\mathrm{PD} / \mathrm{S}$ cells (Fig. 5i), indicating that PDGFR $\alpha$-induced invasion is mediated by SDF-1 signaling in $\mathrm{PD} / \mathrm{S}$ cells. Therefore, these results demonstrated that PDGFR $\alpha$ and SDF-1 signaling crosstalk regulates the invasion capability of L-CSCs and promotes metastasis development in advanced PD/S-SCCs.

\section{PDGFR/SDF-1 signaling crosstalk in cancer cells promotes metastasis in human advanced SCCs}

Advanced and recurrent human PD/S-SCCs of skin induce the expression of $P D G F R A / B$, similarly to mouse $\mathrm{PD} / \mathrm{S}$ SCCs [11]. To determine whether SDFl expression is upregulated in human PD/S-SCCs, we analyzed the expression of this chemokine in a subset of patient $\mathrm{WD} /$ MD-SCCs (G2 grade tumors) and advanced SCCs (G3-G4 grade tumors) (Supplementary Table 1). We found that 
A

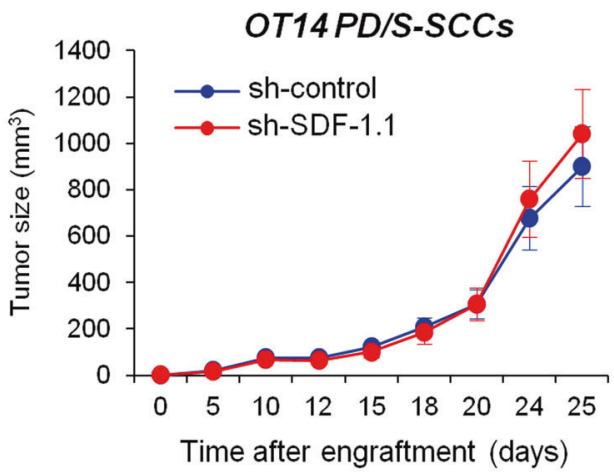

B

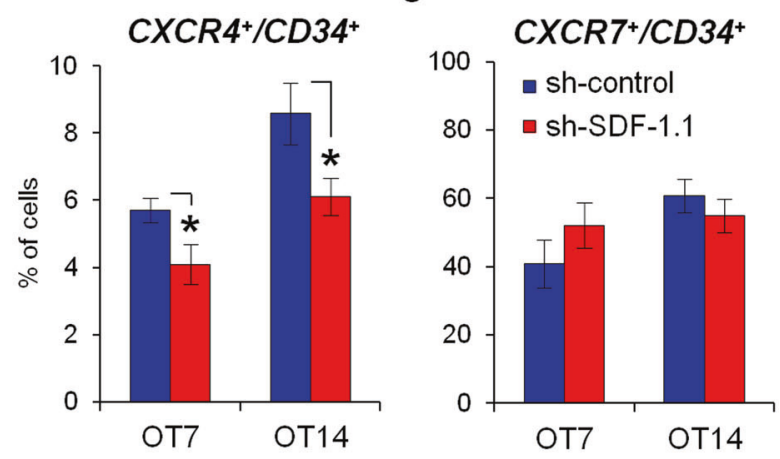

C

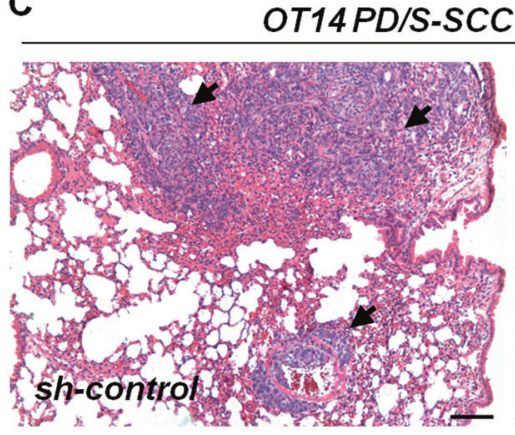

- lung metastasis

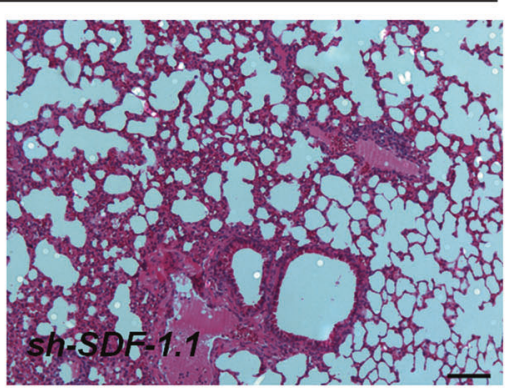

D OT14PD/S-SCC-lung metastasis

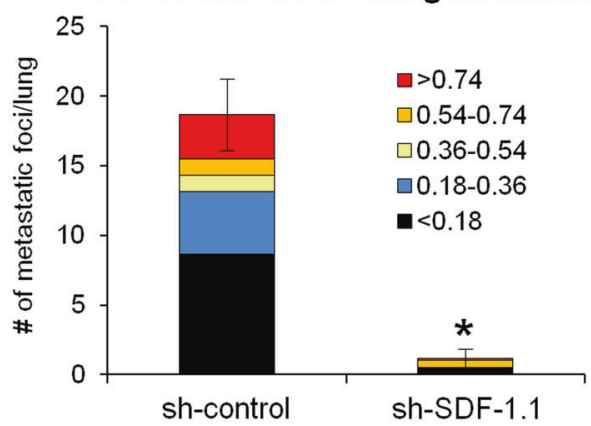

E

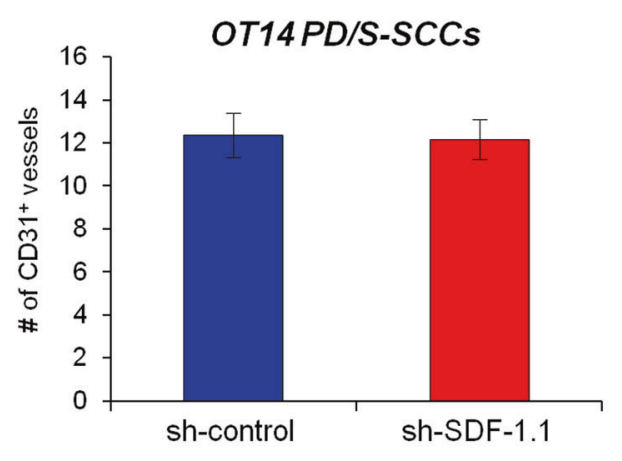

G

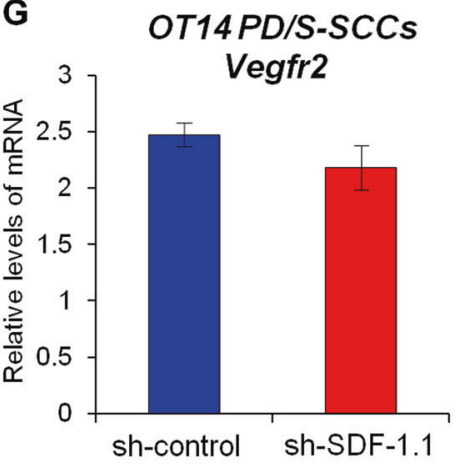

SDF1 and CXCR4 expression was induced in human skin SCCs at late stages of progression, whereas the expression of CXCR7 was not significantly affected (Fig. 6a, c; Supplementary Table 1). Furthermore, a high positive
$\mathbf{F}$
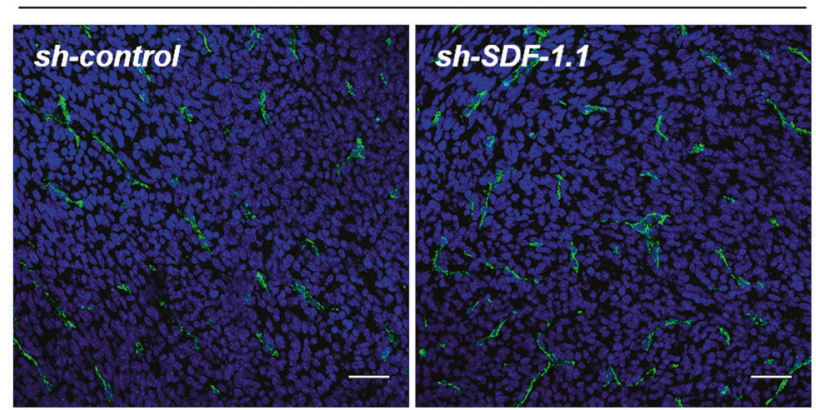

H

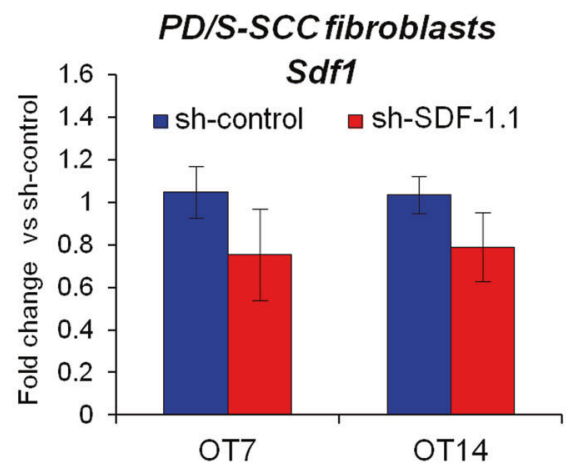

correlation was observed between SDF1 and PDGFRA or $P D G F R B$ expression in this subset of patient tumors (Fig. 6b). SDF-1 was mostly expressed by stromal cells of patient WD/MD-SCCs and was strongly induced in tumor 
Fig. 4 Inhibition of autocrine SDF-1 signaling in L-CSCs blocks metastasis development. a Growth kinetics (mean \pm SE of tumor size, $\mathrm{mm}^{3}$ ) of SDF-1 expressing (sh-control) or SDF-1 knocked-down (shSDF-1.1) PD/S-SCCs (eleven tumors per group). b Mean percentage $( \pm \mathrm{SE})$ of CXCR4- or CXCR7-expressing $\alpha 6$-integrin ${ }^{+} / \mathrm{CD} 34^{+} \mathrm{CSCs}$ in the indicated tumor (7-9 samples per tumor group). c Metastatic lesions (indicated by black arrow) in lungs of immunodeficient mice carrying sh-control or sh-SDF-1.1 PD/S-SCCs. Scale bar, $200 \mu \mathrm{m}$. d Mean of metastatic foci $( \pm$ SE) per lung section (categorized by size, $\mathrm{mm}^{2}$ ) in mice with the indicated PD/S-SCC types (six mice per group), as determined in c. e Mean frequency $( \pm \mathrm{SE}$; 4-6 samples per tumor group) of $\mathrm{CD}_{3} 1^{+}$vessels per tumor section in sh-control and sh-SDF$1.1 \mathrm{PD} / \mathrm{S}-\mathrm{SCCs}$. $\mathbf{f}$ Representative images of the immunodetection of $\mathrm{CD} 31^{+}$vessels in the indicated tumors. Scale bar, $40 \mu \mathrm{m}$. $\mathbf{g}$ Mean level $( \pm \mathrm{SE})$ of Vegfr2 mRNA, relative to Gapdh in the indicated tumors (46 samples per tumor group). h Mean level $( \pm$ SE) of $S d f 1$ mRNA in fibroblasts of sh-SDF-1 PD/S-SCCs, relative to that detected in fibroblasts of sh-control tumors. *, significant differences between the compared groups ( $t$-test; $P \leq 0.05$ )

cells of advanced SCCs (Fig. 6d), in accordance with that observed in mouse SCCs (Fig. 1c). A reduced population of tumor cells expressed CXCR4 in early tumors and this population was expanded in the patient PD/S-SCCs (Supplementary Fig. 6A).

To determine the relevance of SDF-1 signaling in human SCCs, we established primary cultures of tumor cells from a patient WD/MD-SCC (hSCC24 cells) and from a patient $\mathrm{PD} / \mathrm{S}-\mathrm{SCC}$ (hSCC11 cells). hSCC24 WD cells grew as adherent cells and exhibited a typical epithelial shape, whereas $\mathrm{hSCC} 11 \mathrm{PD} / \mathrm{S}$ cells grew forming spheres (Supplementary Fig. 6B). In accordance with the conserved epithelial differentiation traits of patient WD/MD-SCCs [11], hSCC24 WD cells expressed high levels of EpCAM and E-cadherin epithelial markers, whereas hSCC11 PD/S cells lost the expression of these epithelial markers and upregulated the expression of EMT-inducer transcription factors (Supplementary Fig. 6C and 6D). These observations indicate that the EMT program was strongly induced in these human $\mathrm{PD} / \mathrm{S}$ cells. hSCC11 PD/S cells induced the expression and secretion of SDF-1 (Fig. 6e, f), as well as the CXCR4 expression, as compared to hSCC24 WD cells (Fig. 6g). Furthermore, we observed an expansion of the $\alpha 6$-integrin ${ }^{+} / \mathrm{CXCR} 4^{+}$cell population in $\mathrm{hSCC} 11 \mathrm{PD} / \mathrm{S}$ cells (Fig. 6h), consistent with that observed by immunohistochemistry in patient samples. However, CXCR7 expression was significantly downregulated in hSCC11 PD/ $\mathrm{S}$ cells (Fig. 6g), in contrast to what was observed in mouse $\mathrm{PD} / \mathrm{S}$ cells and in other human cutaneous SCC cell lines [34]. In this regard, whereas $89 \%$ of hSCC24 WD cells expressed CXCR7, this population of cells was strongly reduced in hSCC11 PD/S cells (Fig. 6h). These findings suggest that CXCR7 expression in tumor cells may be dependent on intrinsic features and/or the stage of progression of patient tumors. Therefore, these results indicate that SDF-1/CXCR4 signaling is induced in tumor cells of advanced human SCCs.

In addition, a strong upregulation of PDGFR $\alpha$ and PDGFR $\beta$ was detected in hSCC11 PD/S cells (Fig. 6g; Supplementary Fig. 6E), indicating that tumor cells from human advanced SCCs induce PDGFR signaling. Inhibition of PDGFR by Imatinib treatment significantly reduced the expression of $S D F 1$ and in turn, SDF-1 knockdown reduced PDGFRA and PDGFRB expression in hSCC11 PD/S cells (Fig. 6i, j). Therefore, PDGFR signaling controls SDF-1 expression and vice versa, establishing a functional crosstalk between PDGFR/SDF-1 signaling in tumor cells of human advanced SCCs.

CXCR4 knockdown (Supplementary Fig. 6F-6H) or AMD3100 treatment blocked the proliferation of hSCC11 PD/S cells upon basal conditions (Fig. 7a, b). Similarly, abrogation of SDF-1 decreased hSCC11 cell proliferation (Fig. 7c). These findings indicate that an autocrine activation of SDF-1/CXCR4 signaling promotes proliferation of human PD/S-SCCs cells. In accordance with previous findings in mouse PD/S cells [11], no effect on hSCC11 cell proliferation was observed upon PDGFR inhibition by Imatinib treatment (Fig. 7d). However, PDGFR and CXCR4 inhibition significantly reduced the invasion capability of hSCC11 PD/S cells (Fig. 7e, f), indicating that activation of both signaling pathways promotes tumor cell invasion in advanced SCCs.

To determine the impact of PDGFR/SDF-1 signaling in human $\mathrm{PD} / \mathrm{S}-\mathrm{SCC}$ growth and metastasis, hSCC11 $\mathrm{PD} / \mathrm{S}$ cells were engrafted in immunodeficient mice and when tumor growth was detected, mice were treated with Imatinib or AMD3100. In addition, sh-control, sh-CXCR4, and shSDF-1 hSCC11 PD/S cells were engrafted in immunodeficient mice. We found that PDGFR signaling inhibition, SDF-1 abrogation, or CXCR4 inhibition by RNA interference or AMD3100 treatment did not affect human PD/SSCC growth (Fig. 7g-i; Supplementary Fig. 6I). However, inhibition of both PDGFR and SDF-1/CXCR4 signaling pathways significantly reduced the number and size of metastatic lesions developed in the lungs (Fig. 7j-1; Supplementary Fig. 6J).

Together, these results indicate that, similarly to what is described here for mouse advanced SCCs, PDGFR signaling promotes tumor cell invasion and metastasis in human advanced SCCs, which is mediated by the activation of SDF-1 signaling.

\section{Discussion}

High risk and metastatic skin SCCs are occasionally treated with radiotherapy or conventional chemotherapy, but these treatments yield little clinical benefit [6]. Since long-term 
A

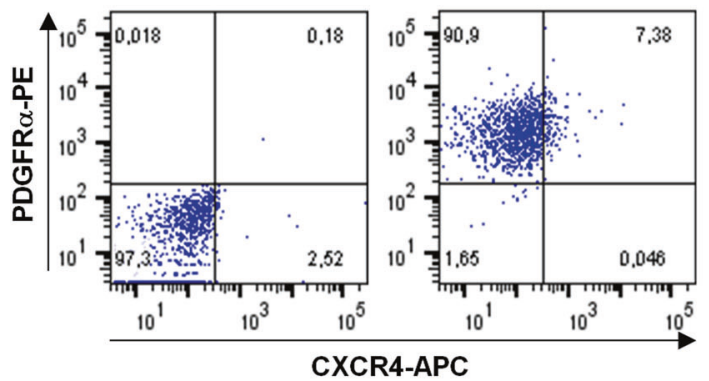

B PDGFR $\alpha$ CXCR4 cells

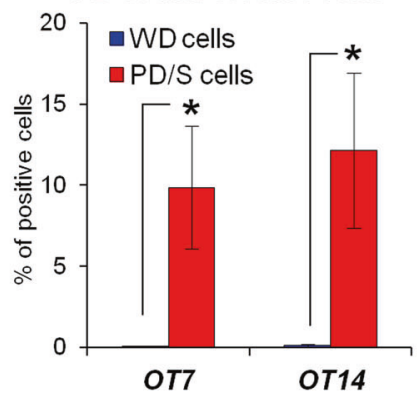

C
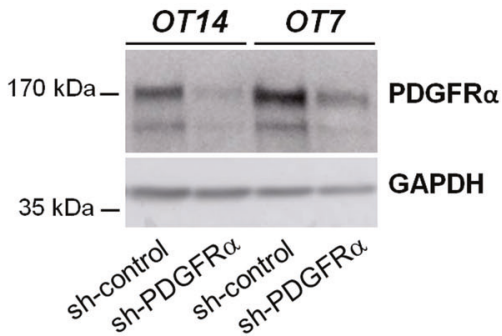

D

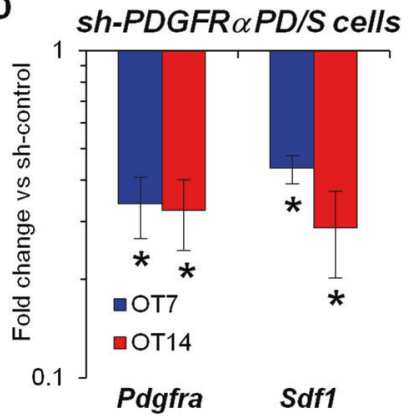

E

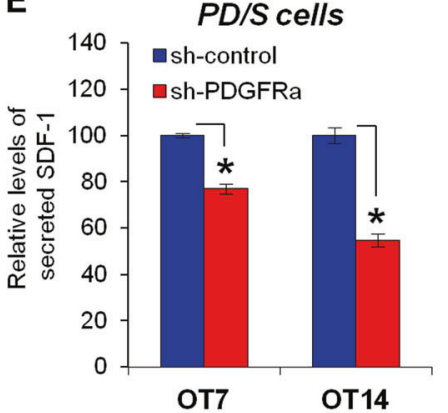

$\mathbf{F}$

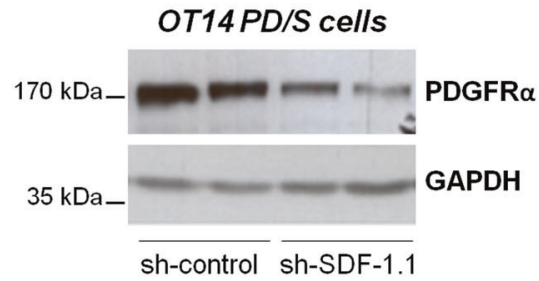

G OT14PD/S cells

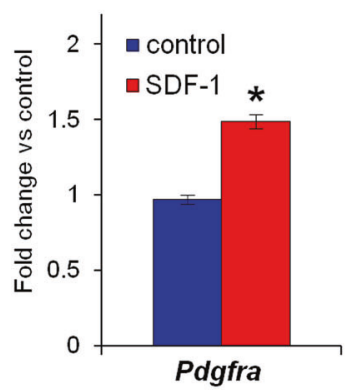

H

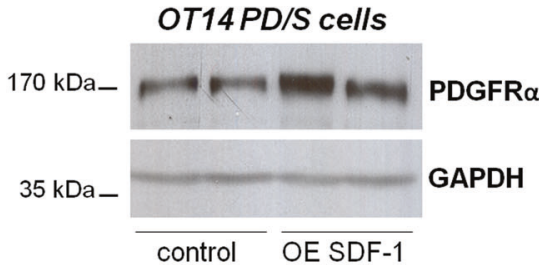

I

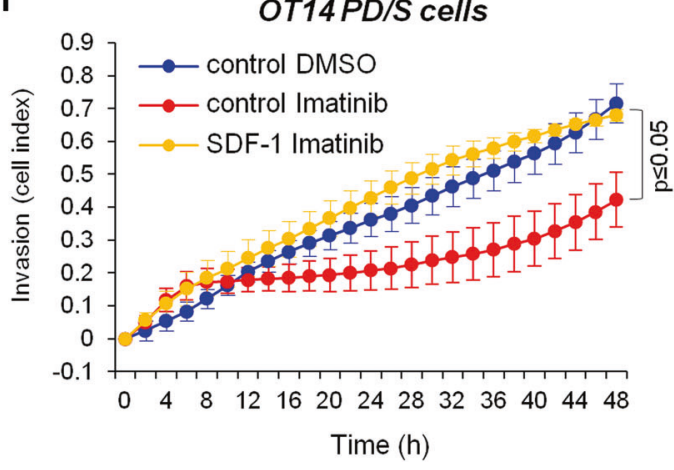

Fig. 5 PDGFR $\alpha$-induced invasion in L-CSCs is mediated by SDF-1 signaling. a Representative results of the quantification by flow cytometry of the percentage of PDGFR $\alpha^{+} / \mathrm{CXCR} 4^{+}$cells in WD and $\mathrm{PD} / \mathrm{S}$ cells. Percentage of each cell population is indicated. b Mean percentage $( \pm$ SE; 3-5 different cell cultures per group and lineage) of $\mathrm{PDGFR}^{+} / \mathrm{CXCR}^{+}$cells in the indicated cell cultures, as analyzed in a. c Representative images of PDGFR $\alpha$ expression in the indicated cells after transduction with sh-control and sh-PDGFR $\alpha$ lentivirus. d Mean mRNA levels $( \pm$ SE) of the indicated genes in sh-PDGFR $\alpha$ PD/ $\mathrm{S}$ cells relative to sh-control PD/S cells of OT7 and OT14 tumor lineages (three different samples per group). e Quantification of SDF-1 concentration (mean $\pm \mathrm{SE}$ ) in the culture medium of the indicated $\mathrm{PD} / \mathrm{S}$ cells by ELISA assays (three samples per group). f Representative

SCC growth is sustained by CSCs [7, 40], it is important to determine mechanisms controlling the proliferation and dissemination of this subset of tumor cells to block the aggressive growth and metastasis associated with advanced SCCs. Although previous studies have demonstrated that SDF-1 signaling promotes tumor growth and metastasis in other cancer types [22-24], the relevance of this signaling images of PDGFR $\alpha$ expression in two independent samples of control and SDF-1-interfered PD/S cells. g Mean Pdgfra mRNA levels $( \pm \mathrm{SE})$ in SDF-1-overexpressing PD/S cells (SDF-1) relative to control cells (transduced with empty vector). h Representative images of PDGFR $\alpha$ expression in two independent samples of control and SDF-1overexpressing PD/S cells (OE SDF-1). i Representative results of the invasion capability (mean cell index $\pm \mathrm{SE}$ ) of control PD/S cells in the absence (control DMSO) or presence of Imatinib $(4 \mu \mathrm{M})$ (control Imatinib) and in Imatinib-treated SDF-1-overexpressing PD/S (SDF-1 Imatinib), as measured by $x$-CELLingence real-time analysis. GAPDH was used as a protein-loading control in $\mathbf{c}, \mathbf{f}$ and $\mathbf{h}$. *, significant differences between the compared groups $(t$-test; $P \leq 0.05)$

pathway in skin SCCs as well as the mechanisms regulating the pathway have been unknown. Here, we demonstrate that PDGFR signaling induces SDF-1 expression and the autocrine activation of SDF-1/CXCR4 signaling in cancer cells and L-CSCs, which promotes the invasion capability of these cells and lung metastasis in mouse and human $\mathrm{PD} / \mathrm{S}-\mathrm{SCC}$. 

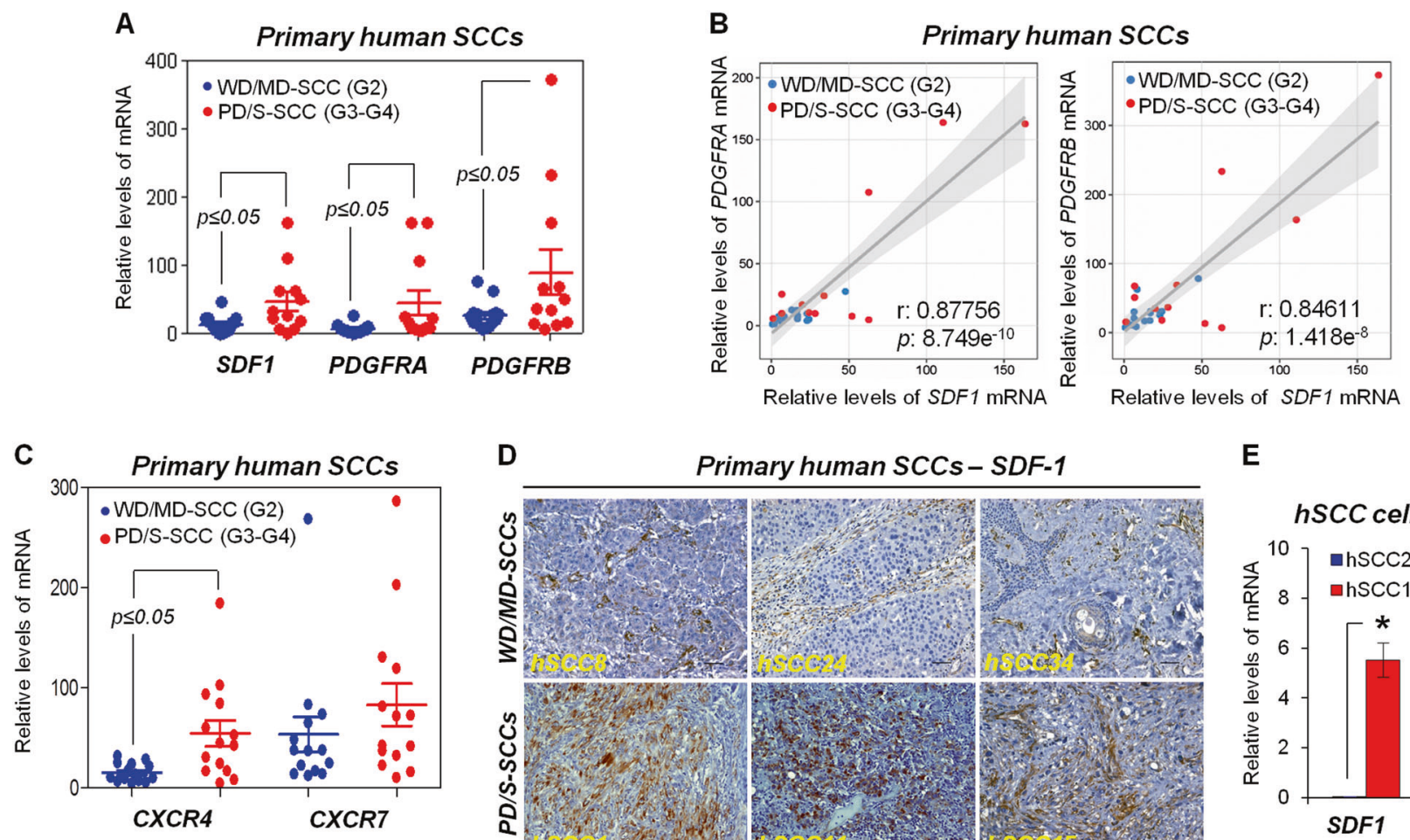

D

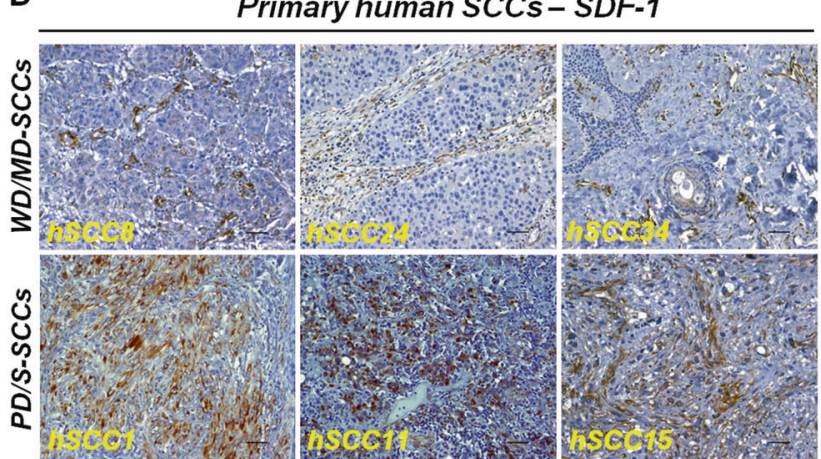

E

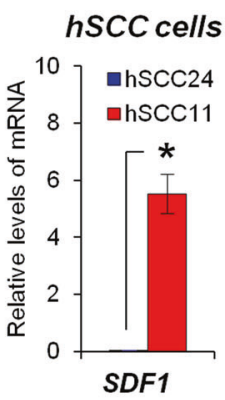

$\mathbf{F}$

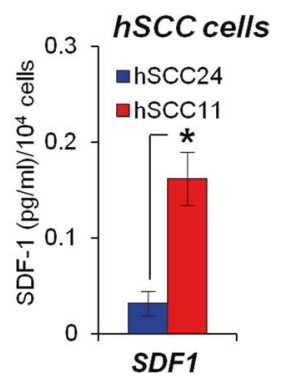

H

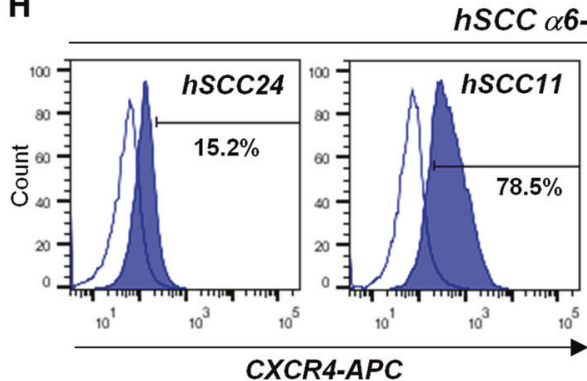

CXCR4-APC
G

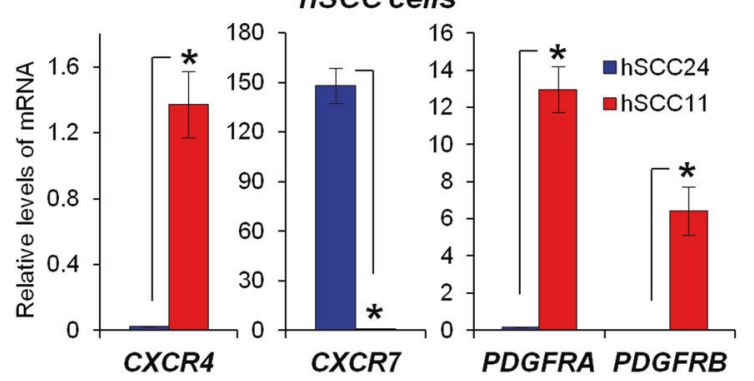

I hSCC11PD/S cells

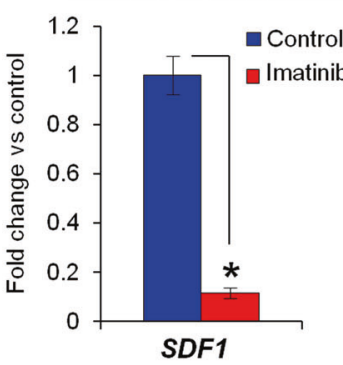

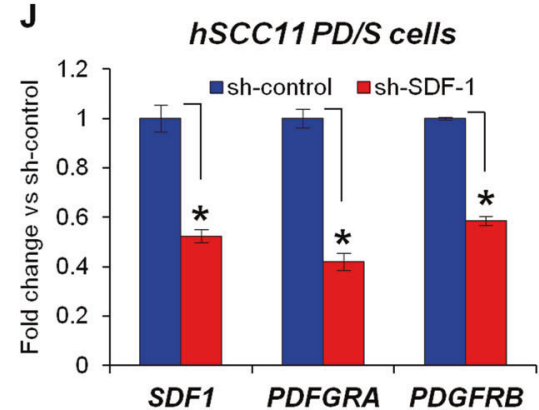

SDF-1 is expressed by stromal fibroblasts in mouse WDSCCs and PD/S-SCCs, and its expression is significantly induced in CSCs of advanced SCCs. More than 50\% of LCSCs express CXCR7, whereas a subset of these cells expresses both CXCR4 and CXCR7 receptors. Therefore, SDF-1 signaling may be activated in these CXCR4/ CXCR7-expressing CSCs not only by paracrine mechanisms, through SDF-1 secreted by the stroma fibroblasts, but also by autocrine mechanisms. We found that inhibition of SDF-1 and CXCR4 in L-CSCs blocks the in vitro proliferation of these cells upon basal conditions, indicating that autocrine activation of SDF-1 signaling promotes L-CSCs proliferation/survival, as previously reported in glioblastoma CSCs $[23,41]$. CXCR4 
Fig. 6 Functional crosstalk between PDGFR and SDF1/ CXCR4 signaling in cancer cells of human advanced SCCs. a mRNA levels of the indicated genes relative to GAPDH (individual data and mean $\pm \mathrm{SE}$ ) in WD/MD-SCC and PD/S-SCC patient samples. $P$ value ( $t$-test) of the compared groups is indicated. b Correlation between $S D F 1$ and PDGFRA or PDGFRB mRNA levels in the indicated patient samples, as determined by Pearson's test. $P$ value is indicated. c mRNA levels of $C X C R 4$ and $C X C R 7$ (individual data and mean \pm $\mathrm{SE})$ in the indicated patient samples. $P$ value ( $t$-test) of the compared groups is indicated. d Representative images of the immunodetection of SDF-1 in paraffin sections of WD/MD-SCCs and PD/S-SCCs patient samples. Scale bar, $100 \mu \mathrm{m}$. e Mean $\left({ }^{+} \mathrm{SE}\right) S D F 1 \mathrm{mRNA}$ levels relative to $G A P D H$, in primary culture cells isolated from human $\mathrm{WD} /$ MD-SCC (hSCC24) and PD/S-SCC (hSCC11). f Mean ( \pm SE) of SDF1 concentration in the culture medium of the indicated cells, as determined by ELISA assays. g Mean $( \pm$ SE) mRNA levels of the indicated genes, relative to GAPDH, in primary culture of hSCC24 and hSCC11 cells. h Quantification of the indicated cell populations in hSCC24 and hSCC11 cells by flow cytometry. Percentage of $\alpha 6-$ integrin $^{+} / \mathrm{CXCR} 4^{+}$and $\alpha 6$-integrin ${ }^{+} / \mathrm{CXCR} 7^{+}$cells is indicated in each panel. $\mathbf{i}, \mathbf{j}$ Mean $( \pm \mathrm{SE})$ of the indicated $\mathrm{mRNA}$ in Imatinib-treated $(4 \mu \mathrm{M}$ for $48 \mathrm{~h})$ relative to those detected in untreated (control) hSCC11 PD/S cells (i), or in sh-SDF-1 relative to sh-control hSCC11 $\mathrm{PD} / \mathrm{S}$ cells $(\mathbf{j})$. *, significant differences between the compared groups $(t$-test; $P \leq 0.05)$

knockdown in L-CSCs significantly reduced PD/S-SCC growth in immunodeficient mice, but not upon a proficient immune system, suggesting that impact of CXCR4 inhibition on tumor growth may be dependent of tumor microenvironment. In addition, abrogation of SDF-1 in L-CSCs had non-effect on in vivo tumor growth. One possible explanation is that stroma-derived SDF-1 drives tumor growth through CXCR7 and/or the remaining CXCR4 receptors of L-CSCs in SDF-1-interfered tumors. Alternatively, under the strong reduction of tumor cell-derived SDF-1, other cytokines or growth factors, produced by stromal cells, may act promoting cancer cell proliferation/ survival and the growth of SDF-1 interfered PD/S-SCCs. Therefore, our results reveal a complex system of tumor growth regulation, implicating not only autocrine and paracrine SDF-1 signaling in tumor cells, but also other pathways probably activated by stroma-derived signals (Fig. 8).

It was proposed that constitutive expression of chemokines in metastasis target tissues is essential for driving metastasis, as CXCR4-expressing cells can home to tissues secreting high levels of SDF-1, such as lymph nodes, bone marrow, or lung [12]. Here, we demonstrated that SDF-1 knockdown or CXCR4 inhibition significantly reduced the in vitro invasion capability of L-CSCs and dramatically reduced the development of lung metastasis, independently of the immune state of mice. Therefore, autocrine SDF-1/ CXCR4 signaling is necessary to facilitate L-CSC migration and invasion and to promote distant metastasis (Fig. 8). Accordingly, autocrine activation of the SDF-1 pathway was reported in various aggressive tumor types with enhanced distant metastasis capability [42, 43]. In addition, ectopic expression of CXCR4 in low metastatic HNSCC cells enables these cells to metastasize to regional lymph nodes, but not to the distant organs [44], whereas the ectopic overexpression of SDF-1 in CXCR $4^{+} \mathrm{HNSCC}$ and breast cancer cells enhanced in vitro cell motility and metastasis in lung [45, 46]. The autocrine activation of SDF-1 signaling described here could be essential for maintaining CXCR4 expression in L-CSCs, although in this scenario the directional homing of these migrating cells to SDF-1-expressing tissues may be disrupted. Furthermore, as SDF-1/CXCR4 signaling induces tumor cell survival (reviewed in [47]), autocrine activation of this signaling may promote migrating cell survival during dissemination or sustain the proliferation of these cells at the distant tissues.

Previous reports described a functional crosstalk between PDGFR and CXCR4 signaling, as activation of PDGFR signaling promotes stability and phosphorylation of CXCR4 in medulloblastoma cells, inducing SDF-1/CXCR4 signaling $[48,49]$. We found that PDGFR $\alpha$ signaling induces SDF-1 expression, which in turn regulates the expression of PDGFR $\alpha$. It is important to highlight that normal keratinocytes and E-CSCs express PDGF ligands, but not PDGFR or SDF-1, which are restricted to stroma cells $[36,50,51]$. In contrast, L-CSCs acquire the expression of PDGFR $\alpha$, allowing not only the autocrine activation of this pathway [11], but also the expression of SDF-1 and the activation of SDF-1/ CXCR4 signaling, which promote L-CSC invasion and metastasis. Furthermore, we observed that L-CSC invasion blockage induced by Imatinib was overridden by the ectopic expression of SDF-1, indicating that SDF-1 mediates PDGFR $\alpha$-induced invasion and metastasis. Although inhibition of PDGFR $\alpha$ reduces Sdfl expression, no significant alterations in tumor cell proliferation or tumor growth were observed following pharmacological or genetic inhibition of PDGFR $\alpha$ in PD/S-SCCs [11], in agreement with that described after SDF-1 knocking-down. Therefore, we suggest that other factors or pathways support tumor growth, but not metastasis, in the absence of PDGFR $\alpha /$ SDF-1 signaling activity.

A similar functional crosstalk between PDGFR and SDF1 was observed in human advanced SCCs. Strong induction of PDGFR $\alpha / \beta$, as well as SDF-1 and CXCR4, was detected in tumor cells of patient PD/S-SCCs, and the inhibition of PDGFR signaling downregulated SDF-1 expression and vice versa. An autocrine activation of SDF-1/ CXCR4 signaling promoted the in vitro proliferation and survival of these cells, although the inhibition of this signaling pathway did not affect human PD/S-SCC growth, following a similar pattern to that here described in mouse $\mathrm{PD} / \mathrm{S}$-SCCs growing in immunocompetent mice. However, the inhibition of PDGFR and SDF-1/CXCR4 signaling in 
A

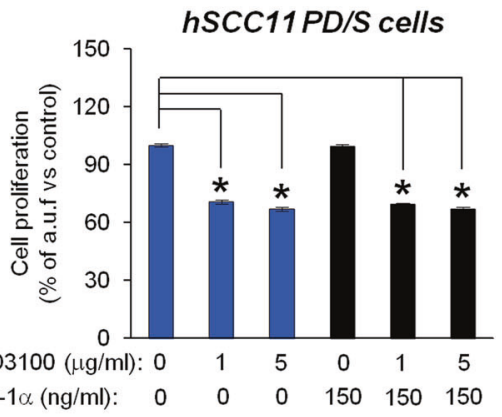

B

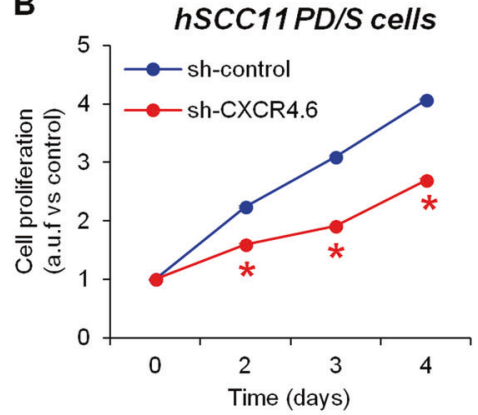

C

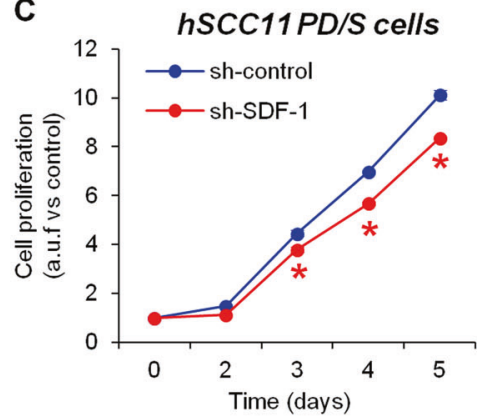

$\mathbf{F}$

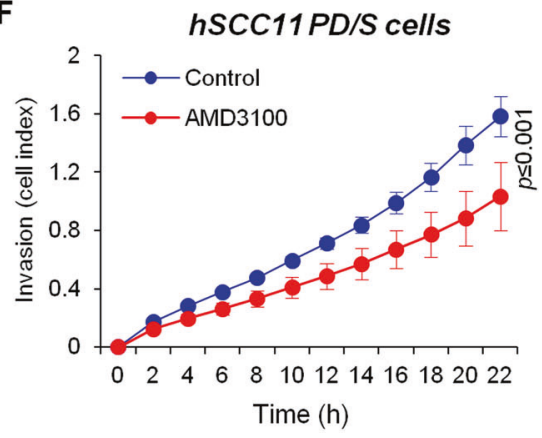

I

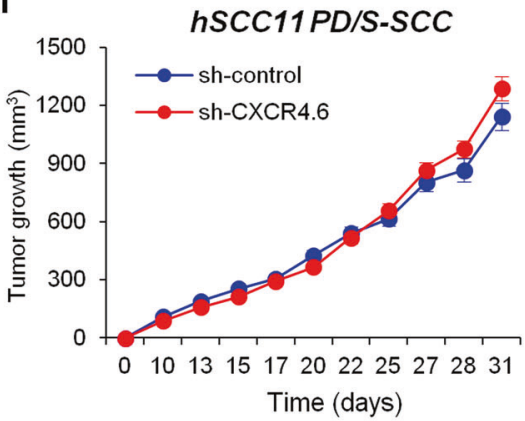

L
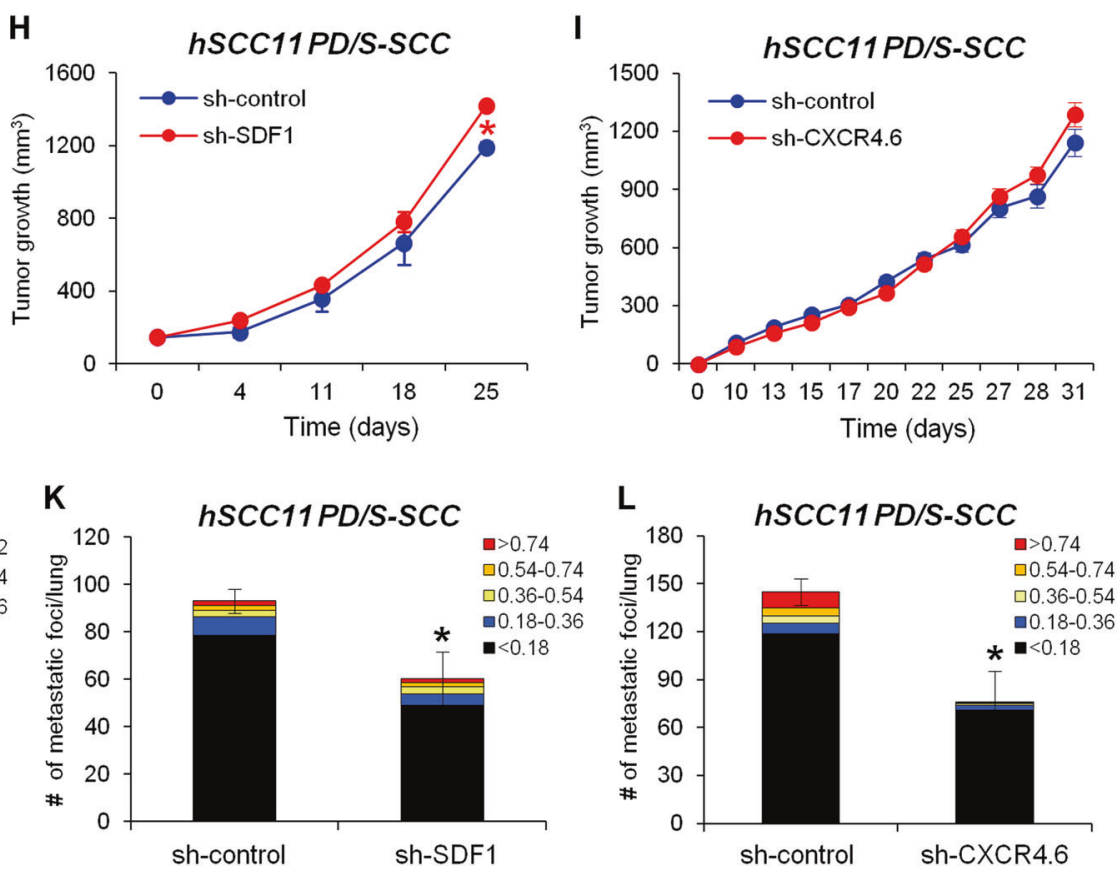

Fig. 7 Inhibition of PDGFR and SDF1/CXCR4 signaling pathways blocks distant metastasis in human PD/S-SCCs. a, d hSCC11 cell proliferation after the indicated treatments, as measured by MTT. Mean $( \pm$ SE) of arbitrary units of fluorescence (a.u.f.) of treated cells relative to cells growing without SDF-1 or AMD3100 (a), or without PDGF or Imatinib (d). b, c Representative proliferation kinetics (means \pm SE of a.u.f. relative to day 0) of control (sh-control) and CXCR4 knocked-down (sh-CXCR4.6) hSCC11 cells (b), or of control and SDF-1 interfered hSCC11 cells (sh-SDF-1) (c), as measured by MTT. e, f Comparison of invasion capacity (mean cell index \pm SE) of hSCC11 PD/S cells upon control or Imatinib treatment (e), or after AMD3100 treatment $(5 \mu \mathrm{g} / \mathrm{mL})$ (f) in $\mathrm{x}$-CELLingence real-time analysis. $\mathbf{g}-\mathbf{i}$ Growth kinetics (mean $\pm \mathrm{SE}$ of tumor size, $\mathrm{mm}^{3}$ ) of tumors generated after engrafting in immunodeficient mice: g hSCC11 cells, which were treated daily with vehicle (control) or Imatinib (nine tumors per group); $\mathbf{h}$ sh-control and SDF-1 knocked down (sh-SDF-1) hSCC11 cells (five tumors per group); and i shcontrol and CXCR4 knocked-down (sh-CXCR4.6) hSCC11 cells (ten tumors per group). $\mathbf{j}-\mathbf{l}$ Mean of metastatic foci $( \pm$ SE) per lung section (categorized by size, $\mathrm{mm}^{2}$ ) developed in: $\mathbf{j}$ control and Imatinib-treated mice (six mice per group); $\mathbf{k}$ sh-control and sh-SDF-1 PD/S-SCCs carrying mice (five mice per group); and $\mathbf{l}$ sh-control and sh-CXCR4 $\mathrm{PD} / \mathrm{S}$-SCCs carrying mice (six mice per group). *, significant differences between the compared groups ( $t$-test; $P \leq 0.05$ ) 


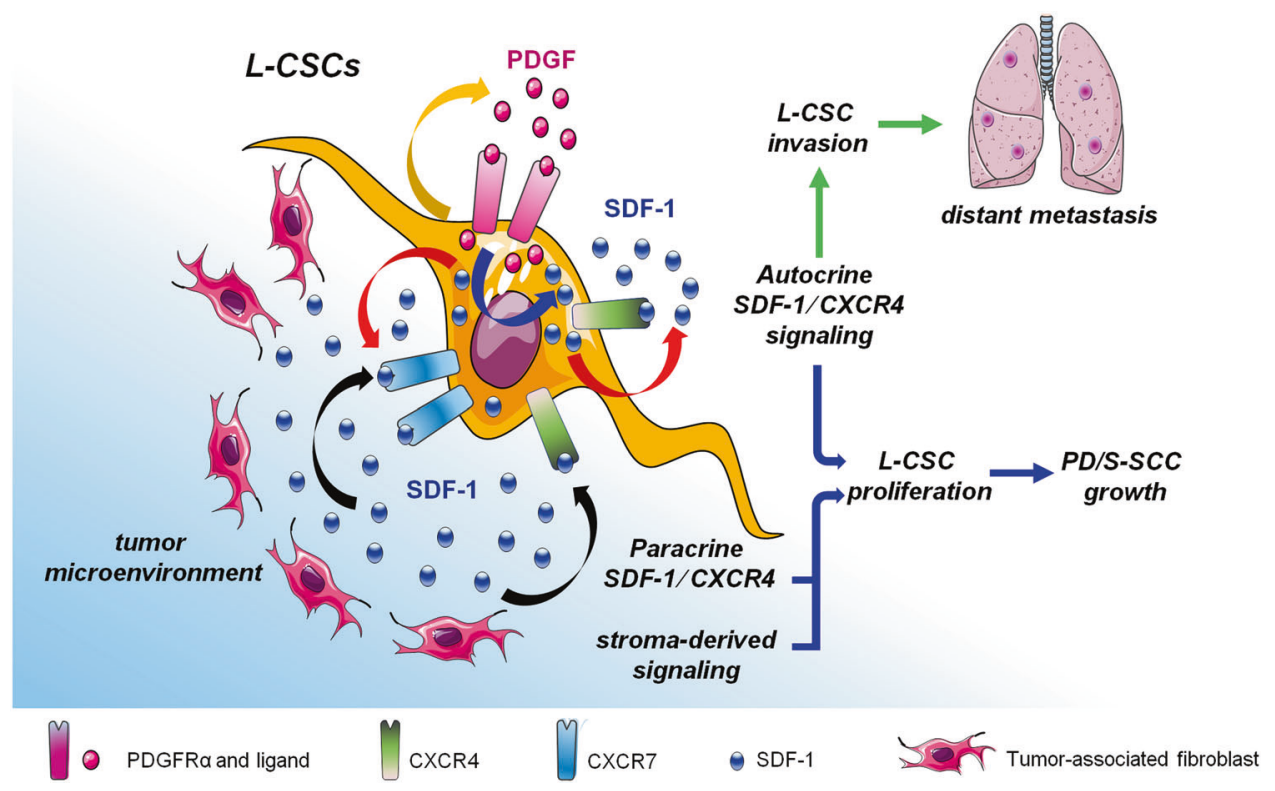

Fig. 8 Impact of PDGFR/SDF-1 signaling crosstalk on PD/S-SCC growth and distant metastasis. Our results indicate that autocrine PDGFR $\alpha$ signaling (orange arrow) induces the expression of SDF-1 (blue arrow) and the autocrine activation of CXCR4/CXCR7 signaling in L-CSCs (red arrows). Fibroblast and stroma-derived SDF-1 can also activate this signaling pathway by a paracrine way (black arrows). Autocrine SDF-1/CXCR4 signaling promotes L-CSC invasion,

human PD/S cells significantly reduced the invasive capacity of these cells and lung metastases development.

Together, our results show that a functional crosstalk between PDGFR/SDF-1 is induced in tumor cells at late stages of mouse and human skin SCC progression, in order to induce autocrine activation of SDF-1/CXCR4 signaling and to promote tumor cell invasion and metastasis. Therefore, the inhibition of PDGFR or/and SDF-1/CXCR4 pathways by currently available drugs, such as Imatinib or AMD3100, may be a possible therapeutic strategy for blocking metastasis development in patients with advanced human skin SCCs.

\section{Material and methods}

\section{Mouse models and lineages of skin SCC generation}

To generate the different lineages of skin SCC progression, small pieces $\left(2-4 \mathrm{~mm}^{3}\right)$ of spontaneous or DMBA/TPAinduced tumor that were developed in K14-HPV $16^{\mathrm{Tg} /+}$ mice (FVB/C57/B16 F1) [52] were engrafted in the back skin of 6-week-old male nude mice (Athymic Nude-Foxn $1^{\text {nu}}$; Harlan Laboratories). Each orthotopic tumor (OT-SCC) was serially engrafted in a new immunodeficient mouse, as previously described [11]. Animal housing, handling, and all procedures involving mice were approved by the promoting distant metastasis development. $\mathrm{PD} / \mathrm{S}-\mathrm{SCC}$ growth may be promoted by the activation of SDF-1/CXCR4 pathway through autocrine or paracrine mechanisms, but also by alternative pathways, which can be activated by stroma-derived factors in response to PDGFR/SDF-1 signaling inhibition. This model shows mouse SCC findings, but can be also applied in human advanced SCCs

Bellvitge Biomedical Research Institute (IDIBELL) ethics committee, in accordance with Spanish national regulations.

\section{Human skin SCC samples}

Samples of human skin SCCs were supplied by the Plastic Surgery and Pathology Units of the Hospital Universitario de Bellvitge (IDIBELL) and the Spanish Hospital Platform Biobank Network (RetBioH; www.redbiobancos.es). The protocol of sample collection was supervised and approved by the Ethical Committee of Clinical Research of Hospital Universitario de Bellvitge (IDIBELL). All patients were informed beforehand and their signed consent to participate was obtained.

\section{SCC cell isolation and flow cytometry analysis}

Tumor cells from skin SCCs were analyzed by flow cytometry, and specific cell populations were isolated by FACSsorter, as described in Supplementary Methods.

\section{Cell cultures}

Tumor cells (hematopoietic lineage and endothelialnegative cells) isolated from mouse WD-SCCs (WD cells) and $\mathrm{PD} / \mathrm{S}-\mathrm{SCCs}(\mathrm{PD} / \mathrm{S}$ cells) from different lineages, and tumor cells isolated from human $\mathrm{PD} / \mathrm{S}-\mathrm{SCCs}$ 
(hSCC11 cells) (see Supplementary Methods for detailed protocol) were grown in DMEM-F12 medium (GIBCO Life Technologies) with $1 \times$ B27 (GIBCO Life Technologies) and penicillin/streptomycin (PAA Laboratories) (basic medium). Tumor cells isolated from human WD/MD-SCCs (hSCC24 cells) were grown in basic medium supplemented with EGF (20 ng/mL; Sigma). Cells were cultured at $37^{\circ} \mathrm{C}$ in a humidified, $5 \% \mathrm{CO}_{2}$ incubator. Protocols for analyzing cell proliferation and for cell transduction are described in detail in the Supplementary Methods.

\section{In vitro invasion assay}

To test the invasion capability of human and mouse tumor cells in response to inhibitor treatments, CIM-16 plates (ACEA Biosciences) coated with 5\% Matrigel (FactorReduced; BD Biosciences) were used. PD/S cells were previously treated without (control) or with AMD3100 (1 and $5 \mu \mathrm{g} / \mathrm{mL}$; Chemscene LLC) and Imatinib (4 $\mu \mathrm{M}$; LC Laboratories) for $48 \mathrm{~h}$, and cells $\left(8 \times 10^{5}, 4-6\right.$ replicates for sample) were seeded in the top chamber, and placed in the xCeLLigence system, maintaining the same concentration of inhibitors in the lower chamber. Each assay was performed twice. The cell index represents the cell invasion capacity.

\section{ELISA assay}

To carry out these analyses, $1.5 \times 10^{6}$ of mouse and human WD and PD/S cells were incubated for $48 \mathrm{~h}$ at $37^{\circ} \mathrm{C}$ in basic medium. The medium was then collected and centrifuged (13,000 r.p.m.) for $10 \mathrm{~min}$ and SDF-1 concentration in the supernatant was analyzed using the PeproTech ELISA kit (Mini ABTS ELISA Development kit) (three replicates per sample), following the manufacturer's recommendations. Substrate solution (TMB Liquid Substrate) was added and incubated for $20 \mathrm{~min}$ at room temperature. The absorbance was measured at $450 \mathrm{~nm}$.

\section{Tumor cell grafting and in vivo treatments}

Sdf1, Cxcr4, and Cxcr7 expression and tumor cell populations expressing these receptors were analyzed in skin SCCs spontaneously developed in male and female K14-HPV16 ${ }^{\mathrm{Tg} /+}$ mice (four samples per group), and in WD-SCCs and PD/SSCCs generated after subcutaneous engrafting WD cells $(1 \times$ $10^{6}$ cells $)$ and PD/S cells $\left(1 \times 10^{4}\right.$ cells $)$ from OT7 and OT14 lineages with Matrigel (1:1; BD Biosciences) in syngeneic immunocompetent mice (6-week-old C57B16/FVB F1 male mice; four samples for group). The impact of CXCR4, CXCR7, SDF1 knockdown on mouse tumor growth and metastasis was studied by subcutaneously co-injecting $4 \times 10^{3}$ sh-control $(n=10)$, sh-CXCR4 $(n=11)$, sh-CXCR7 $(n=11)$, and sh-SDF1 $(n=11)$ mouse PD/S cells with Matrigel (1:1; BD Biosciences) in 6-week-old male nude mice. Following the same protocol, $4 \times 10^{3}$ sh-control $(n=6)$ and sh-CXCR4 $(n=10) \mathrm{PD} / \mathrm{S}$ cells were injected in immunocompetent mice. To test the in vivo effect of CXCR4 and SDF1 knockdown on human PD/S-SCC growth and metastasis, $1 \times 10^{6}$ of shcontrol $(n=15)$, sh-CXCR4 $(n=10)$, and sh-SDF1 $(n=5)$ hSCC11 cells were engrafted in NOD-scid IL2Rg ${ }^{\text {null }}$ (NSG) mice. Tumor growth was monitored and tumors were excised after 25-27 days (mouse SCCs) or 30-32 days (human SCCs), when they reached a critical size. Mice were sacrificed 20 days (mouse PD/S-SCCs) or 10 days (human PD/S-SCCs) after tumor resection. The lungs were recovered and formalin-fixed to quantify the metastatic lesions (5-6 samples per group).

For pharmacological inhibition of CXCR4 in mouse $\mathrm{PD} /$ S-SCCs, $4 \times 10^{3}$ OT14 PD/S cells were subcutaneously engrafted in syngeneic immunocompetent mice. For pharmacological inhibition of PDGFR and CXCR4 in human PD/S-SCCs, $1 \times 10^{6}$ of hSCC11 cells were engrafted in NSG mice. When the tumors were palpable, mice were randomly distributed between control and treated groups, in order that tumor size was similar in both groups at the start of the treatment. Then, mice were intraperitoneally treated with AMD3100 (Glentham Life Sciences; 15 mg/kg; diluted in sterile serum), or serum ( $n=7$ tumors per group for mouse and human SCCs), or orally administered with Imatinib (LC Laboratories; $150 \mathrm{mg} / \mathrm{kg}$; diluted in water) or water ( $n=9$ tumors per group), daily. Tumors were excised when they reached a critical size (20 days post-engraftment) and mice continued to be treated until sacrifice, 10-15 days (for human SCCs) or 20 days (for mouse SCCs) after tumor resection. Then, lungs were recovered and formalin-fixed to quantify the development of the metastatic lesions (5-6 samples per group). Tumors that did not grow after 4-5 weeks of the engraftment or mice that died before the experiment endpoint were excluded.

\section{Histology, immunohistochemistry, and western blot assays}

Tumor and lung samples were fixed in $4 \%$ formaldehyde overnight at $4{ }^{\circ} \mathrm{C}$, paraffin-embedded, and sectioned at $4 \mu \mathrm{m}$. For histopathological analysis and quantification of metastatic lesions, tumor and lung sections were stained with hematoxylin and eosin. Protocols for immunofluorescence assays and western blot analysis are described in detail in the Supplementary Methods.

\section{Reverse transcription and quantitative real-time PCR}

Total RNA was extracted from tumors and cells using Trizol Reagent (Invitrogen). Reverse transcription reactions 
and quantitative real-time PCR were carried out as described in Supplementary Methods.

Acknowledgements AB-P received an IDIBELL Fellowship, VdS-D and PS-E are funded by Spanish Ministry of Science and Innovation Fellowships; the research of PM's group is supported by the Spanish Ministry of Economy and Competitiveness MINECO (SAF201455944R; SAF2017-84976R, co-funded by FEDER funds/European Regional Development Fund (ERDF) — a way to build Europa) and by the Catalan Department of Health (Generalitat de Catalunya; 2017SGR595). We thank J. Comas (Universitat de Barcelona-SCT) for technical support with flow cytometry; the patients enrolled in this study for their participation; the Hospital Universitario Ramón y Cajal, Hospital Virgen de la Salud, Biobanco del Principado de Asturias and Fundación Instituto Valenciano de Oncología, which are members of the Spanish Hospital Platform Biobanks Network; Y. Pérez (Tumor Bank, Hospital de Bellvitge) for help with human tumor sample collection; and the IDIBELL animal facility service for mouse care.

Author contributions AB-P, PS-E, VdS-D, MLdM and LD-G: study conception and design, acquisition, analysis, and interpretation of data; DPS, RMP, OB and JMV: sample collection, analysis, and interpretation; EG-S and FV: data analysis and interpretation; PM: study conception and design, data analysis and interpretation, and manuscript preparation.

\section{Compliance with ethical standards}

Conflict of interest The authors declare that they have no conflict of interest.

Publisher's note: Springer Nature remains neutral with regard to jurisdictional claims in published maps and institutional affiliations.

Open Access This article is licensed under a Creative Commons Attribution 4.0 International License, which permits use, sharing, adaptation, distribution and reproduction in any medium or format, as long as you give appropriate credit to the original author(s) and the source, provide a link to the Creative Commons license, and indicate if changes were made. The images or other third party material in this article are included in the article's Creative Commons license, unless indicated otherwise in a credit line to the material. If material is not included in the article's Creative Commons license and your intended use is not permitted by statutory regulation or exceeds the permitted use, you will need to obtain permission directly from the copyright holder. To view a copy of this license, visit http://creativecommons. org/licenses/by/4.0/.

\section{References}

1. Rogers HW, Weinstock MA, Harris AR, Hinckley MR, Feldman $\mathrm{SR}$, Fleischer AB. et al. Incidence estimate of nonmelanoma skin cancer in the United States, 2006. Arch Dermatol. 2010;146:283-7.

2. Stratigos A, Garbe C, Lebbe C, Malvehy J, del Marmol V, Pehamberger $\mathrm{H}$, et al. Diagnosis and treatment of invasive squamous cell carcinoma of the skin: European consensus-based interdisciplinary guideline. Eur J Cancer. 2015;51:1989-2007.

3. Coussens LM, Hanahan D, Arbeit JM. Genetic predisposition and parameters of malignant progression in K14-HPV16 transgenic mice. Am J Pathol. 1996;149:1899-917.

4. Cherpelis BS, Marcusen C, Lang PG. Prognostic factors for metastasis in squamous cell carcinoma of the skin. Dermatol Surg. 2002;28:268-73.
5. Wong CE, Yu JS, Quigley DA, To MD, Jen KY, Huang PY, et al. Inflammation and Hras signaling control epithelial-mesenchymal transition during skin tumor progression. Genes Dev. 2013;27:670-82.

6. Franco R, Nicoletti G, Lombardi A, Di Domenico M, Botti G, Zito Marino F, et al. Current treatment of cutaneous squamous cancer and molecular strategies for its sensitization to new targetbased drugs. Expert Opin Biol Ther. 2013;13:51-66.

7. Lapouge G, Beck B, Nassar D, Dubois C, Dekoninck S, Blanpain C. Skin squamous cell carcinoma propagating cells increase with tumour progression and invasiveness. EMBO J. 2012;31:4563-75.

8. Boumahdi S, Driessens G, Lapouge G, Rorive S, Nassar D, Le Mercier M, et al. SOX2 controls tumour initiation and cancer stem-cell functions in squamous-cell carcinoma. Nature. 2014;511:246-50

9. da Silva-Diz V, Lorenzo-Sanz L, Bernat-Peguera A, Lopez-Cerda M, Munoz P. Cancer cell plasticity: impact on tumor progression and therapy response. Semin Cancer Biol. 2018;53:48-58.

10. White RA, Neiman JM, Reddi A, Han G, Birlea S, Mitra D, et al. Epithelial stem cell mutations that promote squamous cell carcinoma metastasis. J Clin Invest. 2013;123:4390-404.

11. da Silva-Diz V, Simon-Extremera P, Bernat-Peguera A, de Sostoa J, Urpi M, Penin RM, et al. Cancer stem-like cells act via distinct signaling pathways in promoting late stages of malignant progression. Cancer Res. 2016;76:1245-59.

12. Muller A, Homey B, Soto H, Ge N, Catron D, Buchanan ME, et al. Involvement of chemokine receptors in breast cancer metastasis. Nature. 2001;410:50-6.

13. Liang Z, Wu T, Lou H, Yu X, Taichman RS, Lau SK, et al. Inhibition of breast cancer metastasis by selective synthetic polypeptide against CXC. R4 Cancer Res. 2004;64:4302-8.

14. Smith MC, Luker KE, Garbow JR, Prior JL, Jackson E, PiwnicaWorms D, et al. CXCR4 regulates growth of both primary and metastatic breast cancer. Cancer Res. 2004;64:8604-12.

15. Gelmini S, Mangoni M, Serio M, Romagnani P, Lazzeri E. The critical role of SDF-1/CXCR4 axis in cancer and cancer stem cells metastasis. J Endocrinol Invest. 2008;31:809-19.

16. Kryczek I, Wei S, Keller E, Liu R, Zou W. Stroma-derived factor (SDF-1/CXCL12) and human tumor pathogenesis. Am J Physiol Cell Physiol. 2007;292:C987-95.

17. Darash-Yahana M, Pikarsky E, Abramovitch R, Zeira E, Pal B, Karplus R, et al. Role of high expression levels of CXCR4 in tumor growth, vascularization, and metastasis. FASEB J. 2004;18:1240-2.

18. Folkins C, Shaked Y, Man S, Tang T, Lee CR, Zhu Z, et al. Glioma tumor stem-like cells promote tumor angiogenesis and vasculogenesis via vascular endothelial growth factor and stromalderived factor 1. Cancer Res. 2009;69:7243-51.

19. Miki J, Furusato B, Li H, Gu Y, Takahashi H, Egawa S, et al. Identification of putative stem cell markers, CD133 and CXCR4, in hTERT-immortalized primary nonmalignant and malignant tumor-derived human prostate epithelial cell lines and in prostate cancer specimens. Cancer Res. 2007;67:3153-61.

20. Hermann PC, Huber SL, Herrler T, Aicher A, Ellwart JW, Guba $\mathrm{M}$, et al. Distinct populations of cancer stem cells determine tumor growth and metastatic activity in human pancreatic cancer. Cell Stem Cell. 2007;1:313-23.

21. Bertolini G, Roz L, Perego P, Tortoreto M, Fontanella E, Gatti L, et al. Highly tumorigenic lung cancer CD133+ cells display stemlike features and are spared by cisplatin treatment. Proc Natl Acad Sci USA. 2009;106:16281-6.

22. Ehtesham M, Mapara KY, Stevenson CB, Thompson RC. CXCR4 mediates the proliferation of glioblastoma progenitor cells. Cancer Lett. 2009;274:305-12.

23. Uemae $Y$, Ishikawa E, Osuka S, Matsuda M, Sakamoto N, Takano $\mathrm{S}$, et al. CXCL12 secreted from glioma stem cells regulates their proliferation. J Neurooncol. 2014;117:43-51. 
24. Kong L, Guo S, Liu C, Zhao Y, Feng C, Liu Y, et al. Overexpression of SDF-1 activates the NF-kappaB pathway to induce epithelial to mesenchymal transition and cancer stem cell-like phenotypes of breast cancer cells. Int J Oncol. 2016;48:1085-94.

25. Yang P, Liang SX, Huang WH, Zhang HW, Li XL, Xie LH, et al. Aberrant expression of CXCR4 significantly contributes to metastasis and predicts poor clinical outcome in breast cancer. Curr Mol Med. 2014;14:174-84.

26. Hu TH, Yao Y, Yu S, Han LL, Wang WJ, Guo H, et al. SDF-1/ CXCR4 promotes epithelial-mesenchymal transition and progression of colorectal cancer by activation of the Wnt/beta-catenin signaling pathway. Cancer Lett. 2014;354:417-26.

27. Li X, Li P, Chang Y, Xu Q, Wu Z, Ma Q, et al. The SDF-1/ CXCR4 axis induces epithelial-mesenchymal transition in hepatocellular carcinoma. Mol Cell Biochem. 2014;392:77-84.

28. Burns JM, Summers BC, Wang Y, Melikian A, Berahovich R, Miao Z, et al. A novel chemokine receptor for SDF-1 and I-TAC involved in cell survival, cell adhesion, and tumor development. J Exp Med. 2006;203:2201-13.

29. Naumann U, Cameroni E, Pruenster M, Mahabaleshwar H, Raz E, Zerwes HG, et al. CXCR7 functions as a scavenger for CXCL12 and CXCL11. PLoS ONE. 2010;5:e9175.

30. Tang X, Li X, Li Z, Liu Y, Yao L, Song S, et al. Downregulation of CXCR7 inhibits proliferative capacity and stem cell-like properties in breast cancer stem cells. Tumour Biol. 2016;37:13425-33.

31. Wu YC, Tang SJ, Sun GH, Sun KH. CXCR7 mediates TGFbeta1promoted EMT and tumor-initiating features in lung cancer. Oncogene. 2016;35:2123-32.

32. Quan C, Cho MK, Shao Y, Mianecki LE, Liao E, Perry D, et al. Dermal fibroblast expression of stromal cell-derived factor-1 (SDF-1) promotes epidermal keratinocyte proliferation in normal and diseased skin. Protein Cell. 2015;6:890-903.

33. Basile J, Thiers B, Maize J Sr., Lathers DM. Chemokine receptor expression in non-melanoma skin cancer. J Cutan Pathol. 2008;35:623-9.

34. Hu SC, Yu HS, Yen FL, Chen GS, Lan CC. CXCR7 expression correlates with tumor depth in cutaneous squamous cell carcinoma skin lesions and promotes tumor cell survival through ERK activation. Exp Dermatol. 2014;23:902-8.

35. Chen SJ, Nakahara T, Kido M, Takahara M, Uchi H, Takeuchi S, et al. Stromal cell-derived factor 1 expression in various skin tumours. Br J Dermatol. 2009;160:710-3.

36. Balabanian K, Lagane B, Infantino S, Chow KY, Harriague J, Moepps B, et al. The chemokine SDF-1/CXCL12 binds to and signals through the orphan receptor RDC1 in T lymphocytes. $\mathrm{J}$ Biol Chem. 2005;280:35760-6.

37. Miao Z, Luker KE, Summers BC, Berahovich R, Bhojani MS, Rehemtulla A, et al. CXCR7 (RDC1) promotes breast and lung tumor growth in vivo and is expressed on tumor-associated vasculature. Proc Natl Acad Sci USA. 2007;104:15735-40.

38. Matthys P, Hatse S, Vermeire K, Wuyts A, Bridger G, Henson $\mathrm{GW}$, et al. AMD3100, a potent and specific antagonist of the stromal cell-derived factor- 1 chemokine receptor CXCR4, inhibits autoimmune joint inflammation in IFN-gamma receptor-deficient mice. J Immunol. 2001;167:4686-92.

39. Orimo A, Gupta PB, Sgroi DC, Arenzana-Seisdedos F, Delaunay $T$, Naeem R, et al. Stromal fibroblasts present in invasive human breast carcinomas promote tumor growth and angiogenesis through elevated SDF-1/CXCL12 secretion. Cell. 2005;121:335-48.

40. Nassar D, Blanpain C. Cancer stem cells: basic concepts and therapeutic implications. Annu Rev Pathol. 2016;11:47-76.

41. Gatti M, Pattarozzi A, Bajetto A, Wurth R, Daga A, Fiaschi P, et al. Inhibition of CXCL12/CXCR4 autocrine/paracrine loop reduces viability of human glioblastoma stem-like cells affecting self-renewal activity. Toxicology. 2013;314:209-20.

42. Wang JF, Liu ZY, Anand AR, Zhang X, Brown LF, Dezube BJ, et al. Alpha-chemokine-mediated signal transduction in human Kaposi's sarcoma spindle cells. Biochim Biophys Acta. 2004;1691:129-39.

43. Wang X, Cao Y, Zhang S, Chen Z, Fan L, Shen X, et al. Stem cell autocrine CXCL12/CXCR4 stimulates invasion and metastasis of esophageal cancer. Oncotarget. 2016;8:36149-60.

44. Uchida D, Begum NM, Tomizuka Y, Bando T, Almofti A, Yoshida $\mathrm{H}$, et al. Acquisition of lymph node, but not distant metastatic potentials, by the overexpression of CXCR4 in human oral squamous cell carcinoma. Lab Invest. 2004;84:1538-46.

45. Kang H, Watkins G, Parr C, Douglas-Jones A, Mansel RE, Jiang WG. Stromal cell derived factor-1: its influence on invasiveness and migration of breast cancer cells in vitro, and its association with prognosis and survival in human breast cancer. Breast Cancer Res. 2005;7:R402-10.

46. Uchida D, Onoue T, Tomizuka Y, Begum NM, Miwa Y, Yoshida $\mathrm{H}$, et al. Involvement of an autocrine stromal cell derived factor-1/ CXCR4 system on the distant metastasis of human oral squamous cell carcinoma. Mol Cancer Res. 2007;5:685-94.

47. Sun X, Cheng G, Hao M, Zheng J, Zhou X, Zhang J, et al. CXCL12/CXCR4/CXCR7 chemokine axis and cancer progression. Cancer Metastasis Rev. 2010;29:709-22.

48. Yuan L, Zhang H, Liu J, Rubin JB, Cho YJ, Shu HK, et al. Growth factor receptor-Src-mediated suppression of GRK6 dysregulates CXCR4 signaling and promotes medulloblastoma migration. Mol Cancer. 2013;12:18.

49. Sciaccaluga M, D’Alessandro G, Pagani F, Ferrara G, Lopez N, Warr T, et al. Functional cross talk between CXCR4 and PDGFR on glioblastoma cells is essential for migration. PLoS ONE. 2013;8:e73426.

50. Ponten F, Ren Z, Nister M, Westermark B, Ponten J. Epithelialstromal interactions in basal cell cancer: the PDGF system. J Invest Dermatol. 1994;102:304-9.

51. Pablos JL, Amara A, Bouloc A, Santiago B, Caruz A, Galindo M, et al. Stromal-cell derived factor is expressed by dendritic cells and endothelium in human skin. Am J Pathol. 1999;155:1577-86.

52. Arbeit JM, Munger K, Howley PM, Hanahan D. Progressive squamous epithelial neoplasia in K14-human papillomavirus type 16 transgenic mice. J Virol. 1994;68:4358-68. 